\title{
The Thalamus Regulates Retinoic Acid Signaling and Development of Parvalbumin Interneurons in Postnatal Mouse Prefrontal Cortex
}

\author{
Rachel Larsen," Alatheia Proue," ㅌarl Parker Scott," Matthew Christiansen, and ㄴ) Yasushi Nakagawa
}

https://doi.org/10.1523/ENEURO.0018-19.2019

Department of Neuroscience, University of Minnesota Medical School, Minneapolis, Minnesota 55455

\section{Visual Abstract}

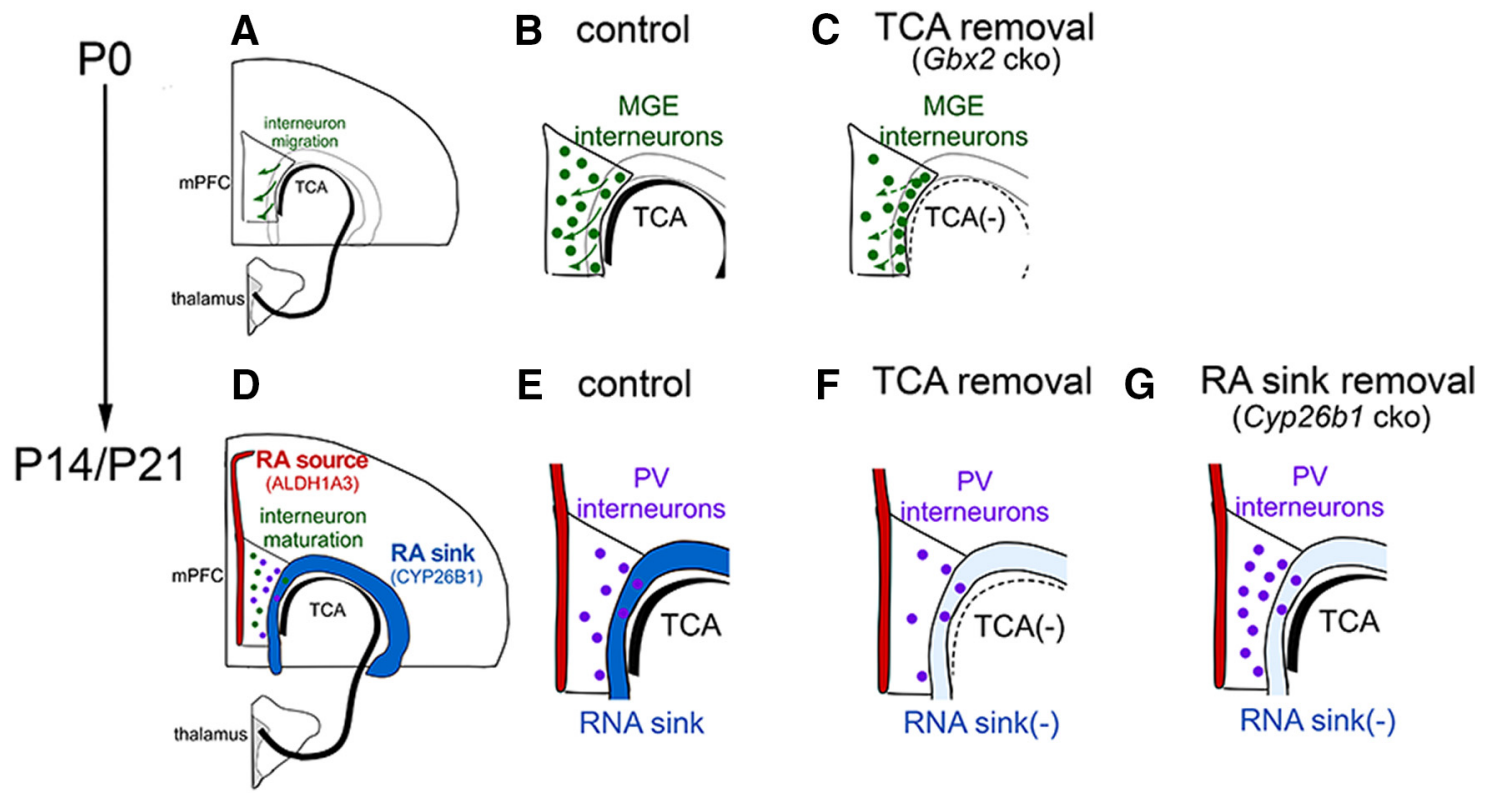

\section{Abstract}

GABAergic inhibitory neurons in the prefrontal cortex (PFC) play crucial roles in higher cognitive functions. Despite the link between aberrant development of PFC interneurons and a number of psychiatric disorders, mechanisms

\section{Significance Statement}

Parvalbumin (PV)-expressing inhibitory neurons in the prefrontal cortex (PFC) play a critical role in excitation-inhibition balance and neuronal synchrony during cognitive tasks, and their abnormality is associated with many developmental brain disorders, including schizophrenia and autism. However, molecular and cellular mechanisms for the development of these neurons are not well understood. In this study, we found that retinoic acid (RA) signaling plays an important role in early postnatal development of prefrontal PV neurons, and that the developmentally regulated expression of a key enzyme that restricts RA signaling in the PFC requires the connections between the thalamus and the neocortex. Thus, our results show a novel role of the thalamus in regulating PV neuron development in postnatal PFC. 
underlying the development of these neurons are poorly understood. Here we show that the retinoic acid (RA)-degrading enzyme CYP26B1 (cytochrome P450 family 26 , subfamily $B$, member 1 ) is transiently expressed in the mouse frontal cortex during postnatal development, and that medial ganglionic eminence (MGE)-derived interneurons, particularly in parvalbumin (PV)-expressing neurons, are the main cell type that has active RA signaling during this period. We found that frontal cortex-specific Cyp26b1 knock-out mice had an increased density of PV-expressing, but not somatostatin-expressing, interneurons in medial PFC, indicating a novel role of RA signaling in controlling PV neuron development. The initiation of Cyp26b1 expression in neonatal PFC coincides with the establishment of connections between the thalamus and the PFC. We found that these connections are required for the postnatal expression of Cyp26b1 in medial PFC. In addition to this regionspecific role in postnatal PFC that regulates RA signaling and PV neuron development, the thalamocortical connectivity had an earlier role in controlling radial dispersion of MGE-derived interneurons throughout embryonic neocortex. In summary, our results suggest that the thalamus plays multiple, temporally separate roles in interneuron development in the PFC.

Key words: Cyp26b1; interneurons; parvalbumin; prefrontal cortex; retinoic acid; thalamocortical

\section{Introduction}

The prefrontal cortex (PFC) integrates many modalities of information to execute higher functions such as goaloriented behaviors, social interactions and emotion. Aberrant development of the PFC has been linked to schizophrenia, autism spectrum disorders, attention deficit hyperactivity disorders, depression, and bipolar disorders (Schubert et al., 2015). More specifically, developmental trajectories of GABAergic interneurons in the PFC, particularly those expressing the calcium-binding protein parvalbumin (PV), are impaired in both human patients and animal models of these disorders (Meechan et al., 2012; Nakazawa et al., 2012; Powell et al., 2012; Gonzalez-Burgos et al., 2015; Caballero and Tseng, 2016; Hashemi et al., 2018). Therefore, determining the devel-

Received January 14, 2019; accepted February 11, 2019; First published February 25, 2019.

The authors declare no competing financial interests.

Author contributions: R.L., A.P., E.P.S., M.C., and Y.N. performed research; R.L., A.P., E.P.S., and Y.N. analyzed data; Y.N. designed research; Y.N. contributed unpublished reagents/analytic tools; Y.N. wrote the paper.

This work was supported by grants to Y.N. from National Institutes of Health (R21-MH-105759), Brain and Behavior Research Foundation (Essel Investigator), Winston and Maxim Wallin Neuroscience Discovery Fund, and Academic Health Center of the University of Minnesota.

${ }^{*}$ R.L., A.P., and E.P.S. contributed equally to the work.

We thank Steven McLoon (University of Minnesota, Minneapolis, MN), Goichi Miyoshi (Tokyo Women's Medical University, Tokyo, Japan), and Timothy Monko (University of Minnesota, Minneapolis, MN) for helpful comments and discussions; Thomas Bao, Samantha Dabruzzi, Shaylene McCue, Morgan McCullough, and Carmen Tso (University of Minnesota, Minneapolis, MN) for technical assistance; and the University of Minnesota Vision Core and Paulo Kofuji for allowing us to use their Olympus confocal microscope. Zachery Werkhoven and Melody Lee (University of Minnesota, Minneapolis, MN) contributed to the initial phase of the project. We also thank Martyn Goulding (Salt Institute, La Jolla, CA) for providing Rosa26 $6^{\text {stop-TeNT/stop-TeNT mice; Hiroshi }}$ Hamada (RIKEN Center for Biosystems Dynamics Research, Kobe, Japan) and Maria Morasso (National Institutes of Health, Bethesda, MD) for providing Cyp26b $1^{\text {flox/flox }}$ mice; Eric Turner (University of Washington, Seattle, WA) for providing Syt6 $6^{\mathrm{Cre} /+}$ mice; Rob Machold for providing Pvalb, Vip, and Sst cDNAs; and John Rubenstein for providing Lhx6 cDNA.

Correspondence should be addressed to Yasushi Nakagawa at nakagawa@umn.edu.

https://doi.org/10.1523/ENEURO.0018-19.2019

Copyright @ 2019 Larsen et al.

This is an open-access article distributed under the terms of the Creative Commons Attribution 4.0 International license, which permits unrestricted use, distribution and reproduction in any medium provided that the original work is properly attributed. opmental mechanisms of PFC interneurons is important for understanding the disease pathophysiology.

Development of cortical interneurons is regulated by both intrinsic and extrinsic mechanisms (Bartolini et al., 2013; Chu and Anderson, 2015; Hu et al., 2017; Wamsley and Fishell, 2017). One key extrinsic cue is the input from the thalamus, which regulates the migration and maturation of these neurons (Sugiyama et al., 2008; MarquesSmith et al., 2016; Tuncdemir et al., 2016; Zechel et al., 2016). However, most studies addressing the role of the thalamic input in interneuron development have been performed on primary visual or somatosensory cortex, leaving the mechanisms in PFC understudied. The delayed maturation of PFC interneurons compared with other cortical areas (Gonchar et al., 2007; Nowicka et al., 2009; Ueno et al., 2017) and the distinct set of thalamic nuclei connected with the PFC (Clascá et al., 2012; Nagalski et al., 2016) suggest the presence of unique extrinsic regulatory mechanisms for interneuron development in the PFC.

One candidate molecule that may play a role in postnatal development of the PFC is retinoic acid (RA), a small molecule derived from vitamin A. RA is critical for many important aspects of brain development, ranging from rostrocaudal patterning of the hindbrain and spinal cord to synaptic plasticity (Maden et al., 1996; Dupé and Lumsden, 2001; Molotkova et al., 2007; Chen and Napoli, 2008; Chatzi et al., 2011). The RA-degrading enzyme CYP26B1 (cytochrome P450 family 26 , subfamily $B$, member 1 ) is crucial in embryonic vertebrate development (Yashiro et al., 2004; Hernandez et al., 2007; Gonzalez-Quevedo et al., 2010). In postnatal mouse neocortex, Cyp26b1 is expressed in the deep layer of the frontal cortex (Allen Brain Atlas). In addition, Aldh1a3, which encodes an RAsynthesizing enzyme, is expressed in the superficial layer of the medial PFC (Wagner et al., 2006). The already established role of RA in embryonic brain development and the unique opposing locations of Cyp26b1 and Aldh1a3 expression imply that the balance between the degradation and production of RA might play an unexplored role in postnatal development of medial PFC.

In this study, we demonstrated that in medial PFC, Cyp26b1 is transiently expressed in layer 6 cells during early maturation of interneurons in the PFC, and that a 
significant subpopulation of PV interneurons is the main cell type that responds to RA. These results led us to hypothesize that RA signaling regulated by Cyp26b1 plays a role in controlling the development of PV interneurons in the PFC. To test this, we generated frontal cortexspecific Cyp26b1 mutant mice and found that these mice had an increased density of PV-expressing neurons in deep layers of medial PFC. We further demonstrated that the postnatal expression of Cyp26b1 in medial PFC is dependent on the connections between the thalamus and PFC. Thus, the thalamus has a postnatal role in regulating the development of PV neurons via inducing the expression of the RA-degrading enzyme CYP26B1 in frontal cortex. Additionally, we found that the thalamus is also required for the radial allocation of $\mathrm{PFC}$ interneurons during embryogenesis. We therefore propose that the thalamus plays multiple crucial roles in interneuron development in the PFC first by controlling their laminar positioning during embryonic stages, and thereafter by restricting the maturation of $\mathrm{PV}$ neurons through the induction of a retinoic acid-degrading enzyme.

\section{Materials and Methods}

\section{Mice}

RARE-LacZ transgenic mice (Rossant et al., 1991) were obtained from The Jackson Laboratory (stock \#008477) and were kept in the CD1 background. Frontal cortexspecific Cyp26b1 mutant mice were generated using BAC (bacterial artificial chromosome) Syt6-Cre mice (GENSAT; Gong et al., 2003; Hsu et al., 2014). Although the endogenous Syt6 (Synaptotagmin 6) gene is expressed ubiquitously in layer 6 of the neocortex, the BAC Cre line caused recombination specifically in the frontal cortex. We crossed Syt6 ${ }^{\mathrm{Cre} /+}$; Cyp26b $1^{\text {flox/+ }}$ mice and Cyp26b $1^{\text {flox/flox }}$ mice to generate the conditional mutants. Cyp26b $1^{\text {flox/flox }}$ mice (Okano et al., 2012) were developed by Dr. Hiroshi Hamada's laboratory (RIKEN Center for Developmental Biology, Kobe, Japan) and obtained from Dr. Maria Morasso (National Institute of Arthritis and Musculoskeletal and Skin Diseases, Bethesda, MD). Rosa26 ${ }^{\text {stop-ZSGreen/+ }}$ (Ai6) mice (Madisen et al., 2010) were obtained from The Jackson Laboratory (stock \#007906). Thalamus-specific Gbx2 mutant mice were generated by crossing Olig ${ }^{\mathrm{Cre} /+}$; Gbx $2^{\text {null/ }+}$ mice and $G b x 2^{\text {flox/flox }}$ mice as described previously (Vue et al., 2013). Gbx2 flox/flox mice were obtained from The Jackson Laboratory (Li et al., 2002). Olig3 ${ }^{\text {Cre/+ }}$ mice were described previously (Vue et al., 2009; Bluske et al., 2012). The Gbx2 $2^{\text {null }}$ allele was generated by crossing $G b x 2^{\text {flox/flox }}$ mice with the CMV-Cre germline deleter mice (stock \#003465, The Jackson Laboratory). Mice that express tetanus toxin light chain (TeNT) in thalamic neurons were generated by crossing Olig $3^{\mathrm{Cre} /+}$ mice and

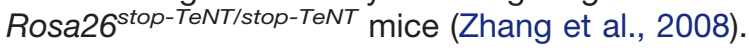

\section{In situ hybridization}

cDNAs for the following genes were used: Cyp26b1, Aldh1a3, Syt6, and Lmo4 (Open Biosystems); Pvalb, Sst, and Vip (obtained from Dr. Rob Machold, New York University); Lhx6 (obtained from Dr. John Rubenstein, University of California San Francisco); and $R O R \beta$ (obtained from Dr. Michael Becker-Andre, Ludwig Maximilians University of Munich). Postnatal pups were perfused with $4 \%$ paraformaldehyde (PFA)/0.1 M phosphate buffer, and the heads were postfixed until needed. Brains were then taken out of the skull, washed in $0.1 \mathrm{M}$ phosphate buffer for $20 \mathrm{~min}$ and were sunk in 30\% sucrose $/ 0.1 \mathrm{M}$ phosphate buffer. Coronal sections were cut with a sliding microtome at $50 \mu \mathrm{m}$ thickness (Leica) or with a cryostat at $20 \mu \mathrm{m}$ [postnatal day 2 (P2) or younger] or $40 \mu \mathrm{m}$ (P4 or older) thickness and were mounted on glass slides (Super Frost Plus, Thermo Fisher Scientific). In situ hybridization was conducted as described previously (Vue et al., 2007).

\section{Immunohistochemistry}

Brains were taken out immediately after perfusion and were postfixed for $1 \mathrm{~h}$ (P0), 1-2 h (P4-P14) or 1-4 h (P21). After the postfixation, the brains were washed in $0.1 \mathrm{M}$ phosphate buffer for 20 min and were sunk in 30\% sucrose/0.1 M phosphate buffer. Sections were cut as described above for in situ hybridization. The following primary antibodies were used: $\beta$-galactosidase $(\beta$-gal; 1:100, goat, catalog \#55976, Cappel; 1:500, chicken, catalog \#ab9361, Abcam); SOX6 (1:100, rabbit, catalog \#ab30455, Abcam); SP8 (1:100, goat, catalog \#sc104661, Santa Cruz Biotechnology); CTIP2 (1:200, rat, catalog \#ab18465, Abcam); TBR1 (1:200, rabbit, catalog \#ab31940, Abcam; 1:200, chicken, catalog \#AB2261, Millipore); PV (1:500, rabbit, catalog \#PV27, SWANT); somatostatin (SST; 1:100, rat, catalog \#MAB354, Millipore); LIM Homeobox 6 (LHX6; 1:50, mouse, catalog \#sc-271433, Santa Cruz Biotechnology); vesicle-associated membrane protein 2 (VAMP2; 1:200, rabbit, catalog \#104 202, Synaptic Systems); NetrinG1 (1:100, goat, catalog \#AF1166, R\&D Systems); and cleaved caspase 3 (1:100, rabbit, catalog \#D175, Cell Signaling Technology). Secondary antibodies conjugated with Cy2, Cy3, or Cy5 were obtained from Jackson ImmunoResearch.

\section{Combined in situ hybridization (Sst) and immunohistochemistry (SOX6)}

In situ hybridization was conducted as described above, except that before proteinase $\mathrm{K}$ treatment, sections were incubated with $0.3 \%$ hydrogen peroxide/PBS for 10 min to block endogenous peroxidase activity. After the hybridization, slides were washed as described above, and were incubated for $30 \mathrm{~min}$ with antidigoxigenin antibody conjugated with peroxidase, followed by two washes in PBS and one wash with TNT solution (TNT: $0.1 \mathrm{M}$ Tris, $\mathrm{pH} 7.5,0.15 \mathrm{M} \mathrm{NaCl}, 0.05 \%$ Tween 20). Sections were then incubated for $\sim 30 \mathrm{~min}$ in Tyramide Plus Fluorescein (Thermo Fisher Scientific) diluted at 1:250, washed twice in TNT solution, and postfixed. Thereafter, immunostaining with anti-SOX6 antibody was conducted as described above.

\section{Imaging and binning}

For cell counting, images of sections that underwent in situ hybridization or immunostaining were taken using an upright microscope (model E800, Nikon) with a $2 \times$ (in situ hybridization) or a $4 \times$ (immunostaining) objective using a digital CCD camera (Retiga EXi, QImaging) and the Open- 

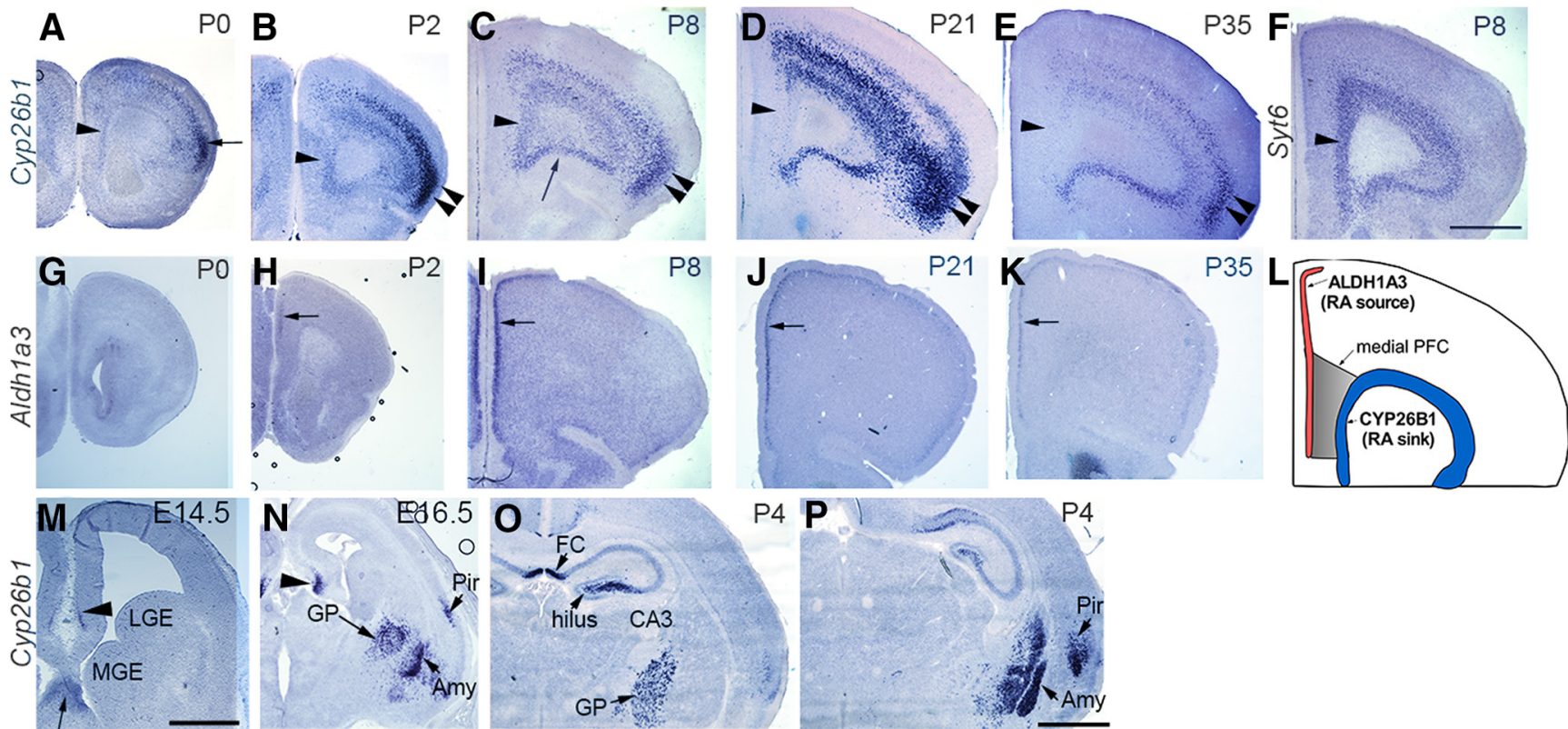

Figure 1. Spatiotemporally regulated expression of Cyp26b1 and Aldh1a3 in the PFC and other forebrain regions. In situ hybridization of frontal sections through PFC at various stages is shown. $\boldsymbol{A}-\boldsymbol{E}$, Cyp26b1 expression in frontal cortex. At P0, only a weak expression is seen in medial PFC $(\boldsymbol{A}$, arrowhead). $\boldsymbol{B}$, At P2, Cyp26b1 starts to be detected clearly in medial PFC (B, arrowhead); expression in lateral cortex, especially agranular insula in more superficial layer $(\boldsymbol{A}$, arrow) is strong, which continues into later stages $(\boldsymbol{B}-\boldsymbol{E}$, double arrowheads). At P8, expression in medial (C, arrowhead) and ventral ( $\boldsymbol{C}$, arrow) PFC is strong. At P21, the expression of Cyp26b1 is reduced in medial PFC ( $\boldsymbol{D}$, arrowhead) and is almost undetectable by P35 (E, arrowhead). $\boldsymbol{F}$, Syt6, a layer 6 marker, is expressed in the same layer as Cyp26b1 in medial PFC at P8 (arrowhead). G-K, Aldh1a3 expression in frontal cortex. At P0, expression is not detected in PFC $(\boldsymbol{G})$. At P2, clear expression is detected in the superficial layer of medial PFC $(\boldsymbol{H}$, arrow). The expression continues into P8, P21, and P35 (I-K, arrow). $\mathbf{L}$, Schematic summary of the spatial expression patterns of Cyp26b1 and Aldh1a3 in medial PFC of early postnatal mouse brains. $\boldsymbol{M}$, Expression of Cyp26b1 is not detected in LGE or MGE at E14.5, but is already found in the hippocampus (arrowhead), septum (arrow), globus pallidus (data not shown), and amygdala (data not shown). N, At E16.5, Cyp26b1 is detected in hippocampus (arrowhead), piriform cortex (Pir), globus pallidus (GP), and amygdala (Amy). $\boldsymbol{O}, \boldsymbol{P}$, This pattern continues into P4 and adulthood (data not shown). $\boldsymbol{P}$ is at a more caudal level than $\boldsymbol{O}$. Expression in the hippocampus is strongest in CA3 and hilus, whereas multiple nuclei in amygdala show strong expression of Cyp26b1 (P). Scale bars: $\boldsymbol{A}-\boldsymbol{K}, \boldsymbol{N}-\boldsymbol{P}, 1 \mathrm{~mm} ; \boldsymbol{M}, 500 \mu \mathrm{m}$.

Lab software. Coronal sections of the rostral cortex that contain the forceps minor (anterior forceps) of the corpus callosum in the center (Fig. $1 A-F$ ) were used for analysis. Sections in which the forceps minor is extending toward the medial surface as well as the sections that include the corpus callosum itself were excluded as being too caudal. Once the sections were selected for each brain, putative prelimbic and infralimbic areas of the medial PFC (Allen Brain Atlas; Paxinos et al., 2006; Van De Werd et al., 2010) were binned for cell counting. As seen in Figure 5, $A$ and $B$, three dorsal-ventral bins were drawn using Photoshop CS5. Each bin is $500 \mu \mathrm{m}$ high at the medial surface. Each of these three bins was further subdivided into smaller bins by their laminar locations; for sections with in situ hybridization, the most superficial layer (layer 1) was defined as the cell-sparse layer on DAPI staining. The remaining cortical wall was divided into three bins with equal widths, resulting in the total of four laminar bins. Layer 1 and the layer underneath it were grouped together and were named superficial layers, and the remaining two layers were named the deep layers. For immunostaining, we used anti-TBR1 (T-Box, Brain 1) antibody for all slides in Cy5 channel and used it as a reference marker of layer 6 . Then, the areas excluding layers 1 and 6 were equally divided into three parts, resulting in five laminar bins (see
Fig. 7). For Figures 2, $F$ and $G$, and $3, K$ and $L$, the portion between layer 1 and layer 6 was divided into two equal parts, resulting in four laminar bins. For high-magnification images shown in Figures 2 and 3, an Olympus FluoView 1000 confocal microscope was used (40× oil; numerical aperture, 1.25).

\section{Cell counting}

Using the ImageJ or Fiji program, the original color images were converted to inverted black and white images, and dark spots were automatically counted by the ITCN (Image-based Tool for Counting Nuclei) plugin. Cell density was calculated by measuring the area of each bin and dividing the cell number by the area of each bin. At least two sections per brain were used for cell counting, and the numbers were averaged to represent the brain. Two brains (mutant and wild type) from the same litter that were processed and analyzed in the same experiment were compared as a pair.

\section{Experimental design and statistical analysis}

Both males and females were used in this study. A paired ratio $t$ test was used for comparing cell counts between Cyp26b1 CKO (conditional knock-out) mice and wild-type littermates as well as Gbx2 CKO and wild-type 

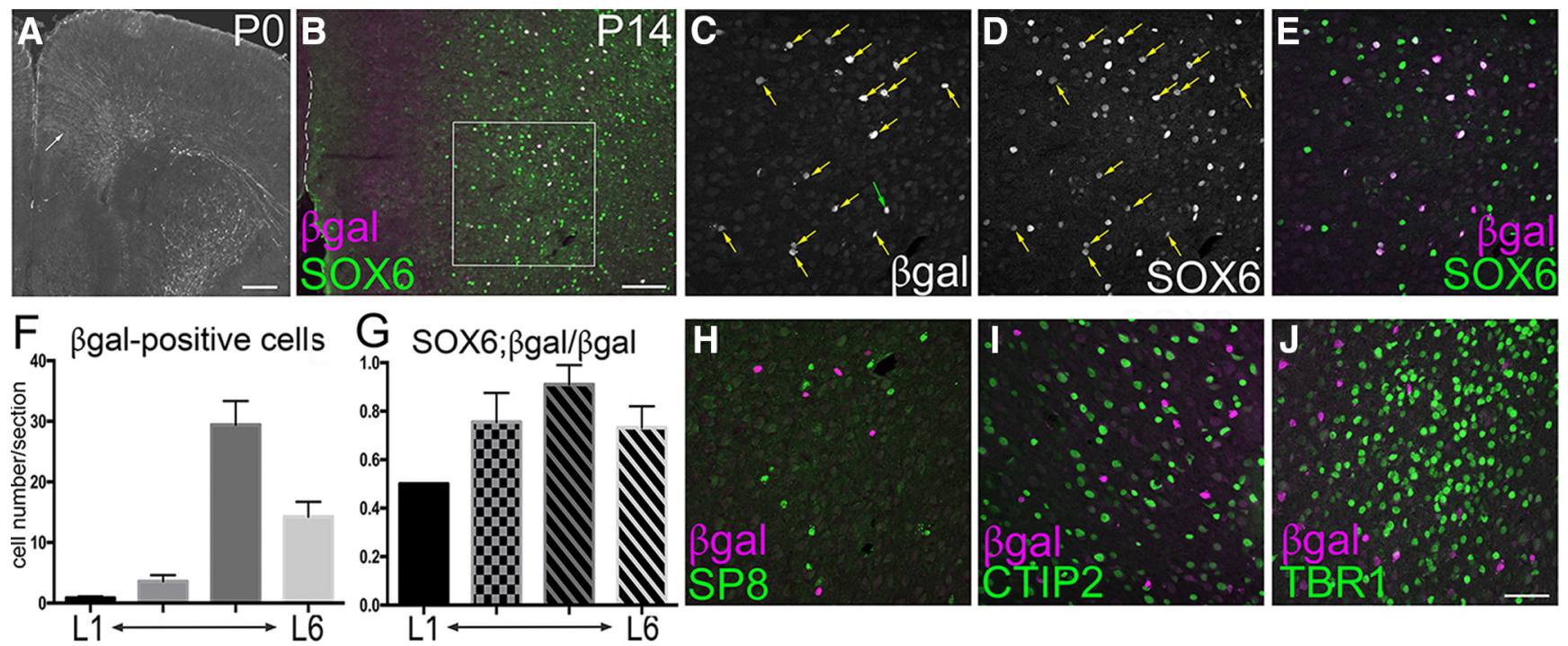

Figure 2. RA signaling in early postnatal PFC. In all sections, the right hemisphere is shown, and the white dashed line marks the medial surface of the frontal cortex. $\boldsymbol{A}-\boldsymbol{E}, \boldsymbol{H}-\boldsymbol{J}$, Immunostaining for $\beta$-gal on frontal sections of P0 $(\boldsymbol{A})$ and $\mathrm{P} 14(\boldsymbol{B}-\boldsymbol{E}, \boldsymbol{H}-\boldsymbol{J})$ brains of $R A R E-L a c Z$ transgenic mice. $\boldsymbol{A}$, At P0, $\beta$-gal expression is found only in the radial glial fibers (arrow). $\boldsymbol{B}-\boldsymbol{J}$, At $\mathrm{P} 14, \beta$-gal-positive cells are abundant in medial PFC and they are SOX6 positive. $\boldsymbol{B}$ is a $10 \times$ image including the medial surface of the brain, and $\boldsymbol{C}-\boldsymbol{E}$ are $40 \times$ confocal images of the same region outlined in the square in $\boldsymbol{B}$. $\boldsymbol{E}$ is the merged image of $\boldsymbol{C}$ and $\boldsymbol{D}$. Yellow arrows in $\boldsymbol{C}$ and $\boldsymbol{D}$ show SOX6/ $\beta$-gal-double-positive cells, and green arrow in $\boldsymbol{C}$ shows a rare, $\beta$-gal-positive, SOX6-negative cell. $\boldsymbol{F}$, Average number of $\beta$-gal-positive cells per section by layers (mean \pm SEM). L1, Layer 1 as marked by sparse labeling in DAPI staining; L6, layer 6 as marked by TBR1 staining. The two middle columns represent equal-width bins between layer 1 and layer 6 , and approximately corresponds to layers $2 / 3$ and layer $4 / 5$, respectively. Because most $\beta$-gal-positive cells are immediately above layer 6 , and layer 4 is thin in medial PFC (Fig. 6G), the highest peak in the third column likely represents layer 5. G, The ratios of SOX6; $\beta$-gal-doublepositive cells among $\beta$-gal-positive cells are shown by layers (mean \pm SEM). $\boldsymbol{H}-\boldsymbol{J}, \boldsymbol{\beta}$-gal does not overlap with SP8, CTIP2, or TBR1. Scale bars: $\boldsymbol{A}, 200 \mu \mathrm{m} ; \boldsymbol{B}, 100 \mu \mathrm{m} ; \boldsymbol{C}-\boldsymbol{E}, \boldsymbol{H}-\boldsymbol{J}, 50 \mu \mathrm{m}$.

littermates. For data seen in Figures 5 and 7, we also performed repeated-measures two-way ANOVA using Prism (versions 6 and 7, GraphPad Software). Graphs were generated using Prism.

\section{Axon tracing}

Small crystals of $1,1^{\prime}$-dioctadecyl-3,3,3'3'-tetramethylindocarbocyanine perchlorate (Dil) were placed on the medial surface of frontal cortex of PFA-fixed P14 Gbx2 conditional mutant brains and their control littermates. After incubation of the brains in PFA at $37^{\circ} \mathrm{C}$ for 2 weeks, we cut sections at $150 \mu \mathrm{m}$ with a vibrating microtome (Oscillating Tissue Slicer, Electron Microscopy Sciences), counterstained the sections, and mounted them on glass slides for imaging.

\section{Results}

\section{Cyp26b1, a gene encoding a retinoic acid-degrading enzyme, is expressed in a spatially and temporally dynamic pattern in postnatal mouse PFC}

To identify genes that are enriched in developing PFC, we screened the Anatomic Gene Expression Atlas (AGEA; $\mathrm{Ng}$ et al., 2009). The database showed that Cyp26b1, a gene that encodes a retinoic acid (RA)-degrading enzyme that belonged to the cytochrome P450 family 26 (CYP26) proteins, is strongly expressed in the frontal cortex at P14, including the deep layer of medial and ventral PFC as well as the middle layer of lateral cortex extending into the agranular insula. We therefore examined the developmen- tal expression patterns of Cyp26b1 in more detail by in situ hybridization. Prenatal cortex did not show detectable Cyp26b1 expression (data not shown). At P0, lateral frontal cortex, but not medial PFC, started to show a robust signal (Fig. 1A). At P2, strong expression of Cyp26b1 was detected in medial PFC, as well as in the dorsolateral frontal cortex including the motor area (Fig. 1B). Comparison with the established marker of layer 6 neurons, Syt6, showed that Cyp26b1 is expressed in layer 6 of medial and ventral PFC (Fig. 1, compare $C$ and $F$ ). Not only was the expression of Cyp26b1 spatially restricted, it was also temporally dynamic; in medial PFC, Cyp26b1 was strong at P8 (Fig. 1C) and P14 (see Fig. 6M). However, by P21, Cyp26b1 expression in medial PFC was much weaker compared with ventral and lateral regions (Fig. 1D). By P35, there was no detectable expression of Cyp26b1 in medial PFC (Fig. 1E).

The tissue RA level is controlled both by its synthesis from vitamin A and by its degradation by CYP26 enzymes. Members of the aldehyde dehydrogenase 1 (ALDH1) family are crucial for synthesizing RA, and two members of this family (ALDH1A2 and ALDH1A3) are expressed in early postnatal cortex; Aldh1a2 is broadly expressed in the meninges (Wagner et al., 2002), whereas Aldh1a3 is specifically expressed in the superficial layer of postnatal medial PFC as well as higher-order visual areas (Wagner et al., 2002, 2006). We found that the expression of Aldh1a3 becomes detectable in medial PFC at P2 (Fig. $1 H$ ). By P8, the expression was robust in layer 2 and 

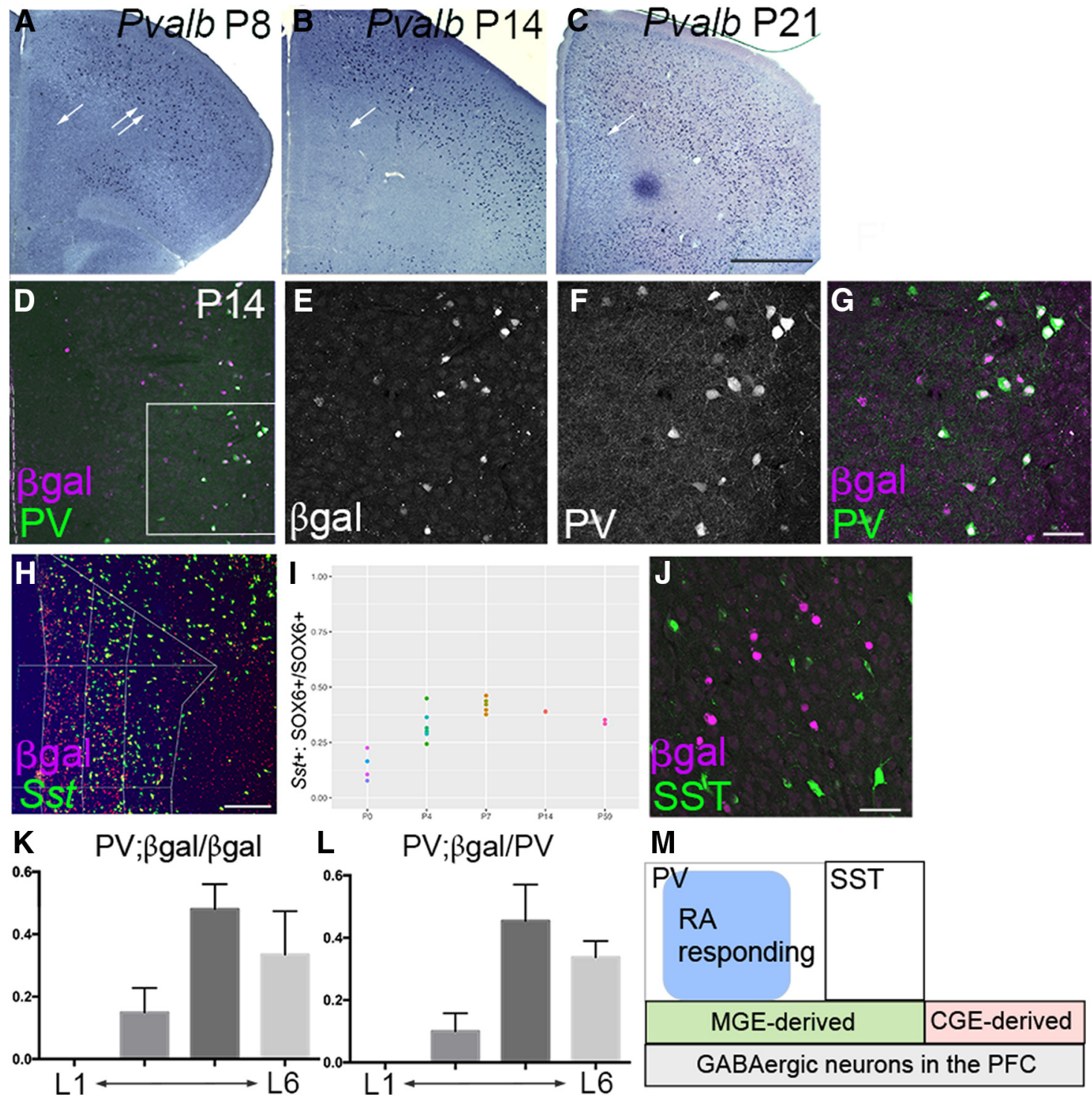

M

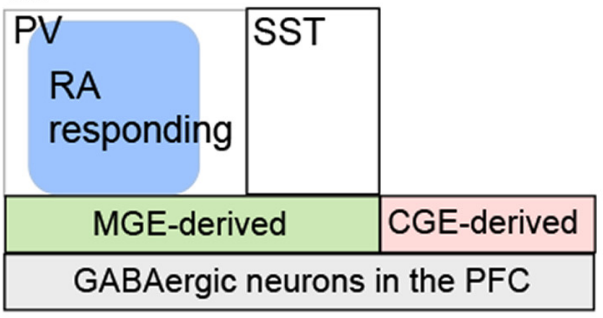

Figure 3. Overlapping expression of RARE-LacZ transgene and PV in early postnatal PFC. A-C, In situ hybridization for $P$ valb mRNA on frontal sections of control mice at P8 (A), P14 (B), and P21 (C). In medial PFC, Pvalb is undetectable at P8, but is robustly expressed at P14, which further increases by P21 (A-C, single arrow). Pvalb mRNA is already expressed in many cells in dorsolateral frontal cortex $(\boldsymbol{A}$, double arrow). $\boldsymbol{D}-\mathbf{G}$, Double immunostaining for $\beta$-gal and PV on frontal sections of P14 brains of $R A R E-L a c Z$ transgenic mice. $\boldsymbol{D}$ is a $10 \times$ image including the medial surface of the brain, and $\boldsymbol{E}-\boldsymbol{G}$ are $40 \times$ confocal images of the same region outlined in the square in $\boldsymbol{D}$. $\boldsymbol{G}$ is a merged image of $\boldsymbol{E}$ and $\boldsymbol{F}$. Note the heavy overlap between $\beta$-gal and PV. $\boldsymbol{H}, \boldsymbol{I}$, Timecourse of Sst expression in medial PFC of postnatal mice. In $\boldsymbol{H}$, Sst mRNA was detected by in situ hybridization using a Tyramide Signal Amplification system, followed by immunostaining with anti-SOX6 antibody. The section is from a control P14 PFC and left is to the medial surface. In I, the ratio of Sst-positive, SOX6-positive cells to SOX6-positive cells in medial PFC is shown for P0, P4, P7, P14, and P59. A plateau value of $\sim 0.4$ is reached by P7. At P0, a much smaller portion of SOX6-positive cells expressed Sst mRNA. Each dot indicates an average number of cells in medial PFC of at least three sections of a wild-type brain. $\boldsymbol{J}$, Double immunostaining for $\beta$-gal and SST on frontal sections of P14 brains of RARE-LacZ transgenic mice. Note the little or no overlap between $\beta$-gal and SST. $K$, The ratios of PV; $\beta$-gal-double-positive cells among $\beta$-gal-positive cells in P14 medial PFC are shown by layers (mean \pm SEM). $L$, The ratios of $\mathrm{PV} / \beta$-gal-double-positive cells among PV-positive cells in P14 medial PFC are shown by layers (mean \pm SEM). $\boldsymbol{M}$, A schematic summary of the interneuron populations in medial PFC. Based on the results of this study, a subpopulation of PV interneurons responds to RA via RAR/RXR receptor complex. Scale bars: $\boldsymbol{A}-\boldsymbol{C}, 1 \mathrm{~mm} ; \boldsymbol{D}, 100 \mu \mathrm{m} ; \boldsymbol{E}-\mathbf{G}, \boldsymbol{J}, 50 \mu \mathrm{m} ; \boldsymbol{H}, 200 \mu \mathrm{m}$.

extended more laterally (Fig. 1/). A similar pattern of expression was found at P21 (Fig. 1J) and P35 (Fig. 1K). There also appears to be Aldh1a3 expression in medial cortex in adult mice (Allen Brain Atlas). Outside of the frontal cortex, we did not detect Cyp26b1 expression in more caudal parts of the neocortex including sensory areas at any developmental stage examined (Figs. 1N,O, 4L). Cyp26b1 was also expressed in the piriform cortex, the amygdala, CA3 and the hilus regions of the hippocampus, and the globus pallidus (Fig. $1 N-P$ ). Expression in these regions started during embryogenesis (Fig. 1N) and continued into adulthood (Allen Brain Atlas). Cyp26b1 was 

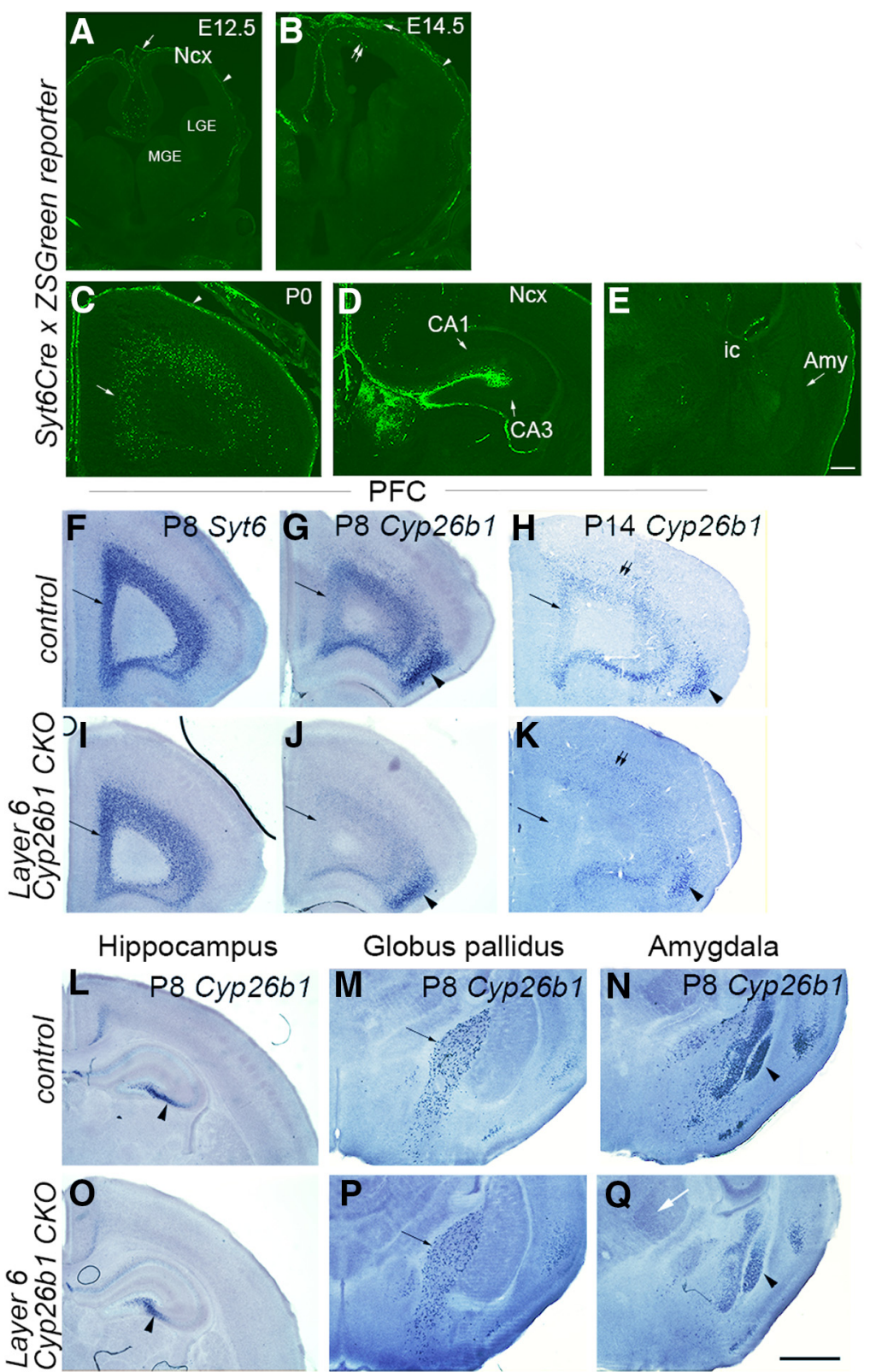

Figure 4. Conditional deletion of Cyp26b1 using Synaptotagmin6-Cre (Syt6-Cre). A-E, Recombination in Syt6-Cre transgene mice. A-E, Expression of ZSGreen in Syt6-Cre/+; Ai6 (ZSGreen Cre reporter) mice at E12.5 (A), E14.5 (B), and P0 (C-E) are shown. All sections are coronal, and the midline is to the left. At E12.5, the expression of ZSGreen reporter is found in meninges $(\boldsymbol{A}$, arrow) and preplate $(\boldsymbol{A}$, arrowhead), but not in the rest of the cortex or MGE and LGE. At E14.5, a small number of cortical cells (B, double arrows) below the marginal zone (B, arrowhead) start to express ZSGreen. $\boldsymbol{C}-\boldsymbol{E}$, At P0, many layer 6 cells of frontal cortex express ZSGreen (C, arrow), but not in more caudal neocortex ( $\boldsymbol{D}, \mathrm{Ncx}), \mathrm{CA} 1, \mathrm{CA} 3$, and hilus regions of the hippocampus ( $\boldsymbol{E}$, note that strong signal is found in the meninges of the hippocampus) or the amygdala ( $\boldsymbol{F}$, Amy). ic, Internal capsule. Scale bar, $200 \mu \mathrm{m}$. $\boldsymbol{F}-\boldsymbol{Q}$, Generation of conditional Cyp26b1 knock-out mice. $\boldsymbol{F}-\mathbf{Q}$, In situ hybridization of frontal sections of P8 (F, G, I, J, $\mathbf{L}-\mathbf{Q})$ or P14 (H, $\boldsymbol{K})$ Cyp26b1 conditional knock-out (I-K, O-Q) and control littermate $(\boldsymbol{F}-\boldsymbol{H}, \boldsymbol{L}-\mathbf{N})$ brains. Cyp26b1 was conditionally knocked out using the Syt6-Cre transgene. Syt6 is expressed in layer 6 of both control $(\boldsymbol{F})$ and Cyp26b1 knock-out (I) brains (arrow). The expression of Cyp26b1 in layer 6 of frontal cortex (arrow) is detected in control brains, but not in Cyp26b1 knock-out brains at P8 $(\boldsymbol{G}, \boldsymbol{J})$ and P14 $(\boldsymbol{H}, \boldsymbol{K})$. The expression of Cyp26b1 in agranular insula is unchanged in Cyp26b1 knockouts ( $\boldsymbol{G}, \boldsymbol{H}, \boldsymbol{J}, \boldsymbol{K}$, arrowhead). The expression of Cyp26b1 in CA3 and hilus region of the hippocampus (L, $\mathbf{O}$, arrowhead), globus pallidus $(\boldsymbol{M}, \boldsymbol{P}$, arrow), and amygdala $(\boldsymbol{N}, \boldsymbol{Q}$, arrowhead) is unchanged in Cyp26b1 knockouts. Scale bar, $1 \mathrm{~mm}$.

not detected in either medial ganglionic eminence (MGE) or lateral ganglionic eminence (LGE; Fig. 1M).

In summary, in the medial part of early postnatal PFC, RA is produced by cells in the superficial layer, whereas CYP26B1, an RA-degrading enzyme or "RA sink," is located in layer 6 (Fig. $1 L)$. These results suggest that RA signaling is spatially and temporally controlled, and that this regulation might play a role in the development of medial PFC. 


\section{Parvalbumin-expressing interneurons in medial PFC respond to retinoic acid during early postnatal development}

The spatiotemporal expression pattern of Cyp26b1 prompted us to explore the cellular targets of RA signaling during postnatal PFC development. To determine the populations of cells that respond to RA, we analyzed the expression of the RARE-LacZ transgene, an indicator of the transcriptional activity of the RA receptor RAR (retinoic acid receptor)/RXR (retinoid X receptor) heterodimers (Rossant et al., 1991). At P0, the expression of $\beta$-gal was barely detectable in medial PFC except in radial glial fibers (Fig. 2A). At P14, a robust population of $\beta$-galpositive cells was detected in medial PFC, mostly in layer 5. These cells were also positive for SOX6, a marker for GABAergic interneurons derived from MGE (Batista-Brito et al., 2009; Fig. 2B-F). Analysis of three transgenic brains revealed that $91 \%$ of $\beta$-gal-positive cells in layer 5 were also SOX6 positive (Fig. 2G). Markers of other neuronal types, including SP8 [Fig. $2 \mathrm{H}$; caudal ganglionic eminence (CGE)-derived cortical interneurons; $\mathrm{Ma}$ et al., 2012], CTIP2 (Fig. 2/; layer 5 subcerebral projection neurons as well as some interneurons; Arlotta et al., 2005; Chen et al., 2005; Nikouei et al., 2016), and TBR1 (Fig. 2J; layer 6 corticothalamic projection neurons; Hevner et al., 2001) did not overlap with $\beta$-gal, indicating that these types of neurons do not express the molecular machinery for responding to RA via RAR/RXR heterodimers. In summary, MGE-derived interneurons in layer 5 are the main responders to RA within early postnatal medial PFC.

Most MGE-derived interneurons in the adult neocortex express either SST or PV (Fogarty et al., 2007; Miyoshi et al., 2007). A majority of these interneurons complete their tangential migration into the neocortex by birth (Miyoshi and Fishell, 2011; Inamura et al., 2012). However, PV protein or Pvalb mRNA is not expressed until much later, suggesting that the expression of PV or Pvalb is a useful marker of maturation for this lineage of cells. At P8, Pvalb mRNA was already abundant in the lateral portion of the neocortex including motor area (Fig. $3 A$, double arrows), but not in medial PFC (Fig. $3 A$, arrow). Thus, maturation of PV neurons is delayed in medial PFC. By P14, cells expressing Pvalb mRNA or PV protein were clearly detectable in medial PFC, mainly in layer 5 (Fig. 3B, arrow), which further increased by P21 (Fig. 3C, arrow).

To determine whether RA-responding cells are restricted to either PV or SST neurons, we next analyzed $R A R E-L a c Z$ transgenic mice to determine the colocalization of $\beta$-gal and PV (Fig. $3 D-G$ ) as well as $\beta$-gal and SST (Fig. $3 \mathrm{~J}$ ) at P14. We found a heavy overlap between PV and $\beta$-gal; in three P14 brains (Fig. $3 D-G$ ), $48 \%$ percentage of $\beta$-gal-positive cells in layer 5 were also PV positive (Fig. $3 K$ ). In turn, $45 \%$ of PV-positive cells in layer 5 were also $\beta$-gal-positive (Fig. $3 L$ ). Similar patterns were found at P21 (data not shown). In a sharp contrast, SST showed very little overlap with $\beta$-gal from P8 through P67 (Fig. 3J; and data not shown); the ratio of SST/ $\beta$-gal doublepositive cells to SST-positive cells was $2.9 \%$ (3 of 103) at P14 and 5.0\% (6 of 121) at P21. In medial PFC, cells expressing SST protein or Sst mRNA appeared between
P0 and P4; by P7, $\sim 40 \%$ of MGE-derived interneurons that express SOX6 also expressed Sst mRNA, and this ratio stayed constant until P59 (Fig. $3 H, I)$. Thus, by P7, most SST neurons in medial PFC already express Sst mRNA, and MGE-derived interneurons that are $\beta$-galpositive and SST-negative are most likely to be PV neurons (Fig. 4M).

\section{Cyp26b1 is required for normal development of parvalbumin-expressing interneurons in medial PFC}

Because of the strong correlation between the expression of PV and the responsiveness of the cell to RA, we hypothesized that the development of PV interneurons in medial PFC is regulated by RA signaling and that this regulation depends on CYP26B1. To test this, we generated conditional Cyp26b1 mutant mice in which Cyp26b1 is deleted in the PFC. Because the expression of Cyp26b1 is highly specific to layer 6 in the frontal cortex, we used Syt6-Cre driver mice (Gong et al., 2003; Hsu et al., 2014). Expression Syt6 is specific to layer 6 in the neocortex (Fig. $1 F$ ), and Syt6-Cre mice allow recombination in layer 6 corticothalamic projection neurons in the frontal cortex including the medial PFC (Allen Brain Atlas; http://connectivity.brain-map.org/). To validate the usefulness of Syt6Cre in knocking out Cyp26b1 in layer 6 of the postnatal frontal cortex but not in other, potentially relevant Cyp26b1-expressing cell populations, we first bred the Cre mice with ZSGreen Cre reporter mice (Ai6; Madisen et al., 2010). At embryonic day 12.5 (E12.5), Syt6-Cre; Ai6 brains showed ZSGreen expression in the preplate and the meninges but not in other parts of the cortex or in ganglionic eminences (Fig. 4A). Cortical expression of ZSGreen started to be detected at E14.5 (Fig. 4B). At P0, robust signs of recombination were seen in layer 6 of the frontal cortex but not in more caudal cortex (Fig. 4C,D), amygdala (Fig. $4 E$ ), or CA3 and hilus regions of the hippocampus (Fig. 4D). Thus, we predicted that the Syt6-Cre mice would cause specific deletion of Cyp26b1 in layer 6 cells of the frontal cortex including medial PFC. In Syt6Cre/+; Cyp26b1 $1^{\text {flox/flox }}$ (Cyp26b1 CKO) mice, Cyp26b1 mRNA was not detected in medial PFC (Fig. 4, compare $G, J$ and $H, K)$, whereas expression in other brain regions including the hippocampus (Fig. 4L,O), agranular insula (Fig. $4 G, J$ ), globus pallidus (Fig. $4 M, P$ ), or amygdala (Fig. $4 N, Q$ ) was not affected, confirming an efficient and specific deletion of Cyp26b1.

We then counted Pvalb mRNA-expressing neurons and compared the numbers between Cyp26b1 CKO mice and their littermate wild-type controls at P14 and P21 (Fig. 5). At both stages, the density of Pvalb-positive cells was significantly increased in medial PFC of Cyp26b1 mutant mice (Fig. 5C,F, "total"). When the PFC was divided into superficial and the deep layers, the difference was seen only in the deeper half of the medial PFC, consistent with the distribution of $\beta$-gal-expressing cells. With repeatedmeasures two-way ANOVA, we also detected significant differences both between layers and between genotypes (Fig. 5, legend). In the motor cortex, we detected a significant increase in the density of $P v a l b$-expressing cells in deep layers of Cyp26b1 CKO mice compared with con- 

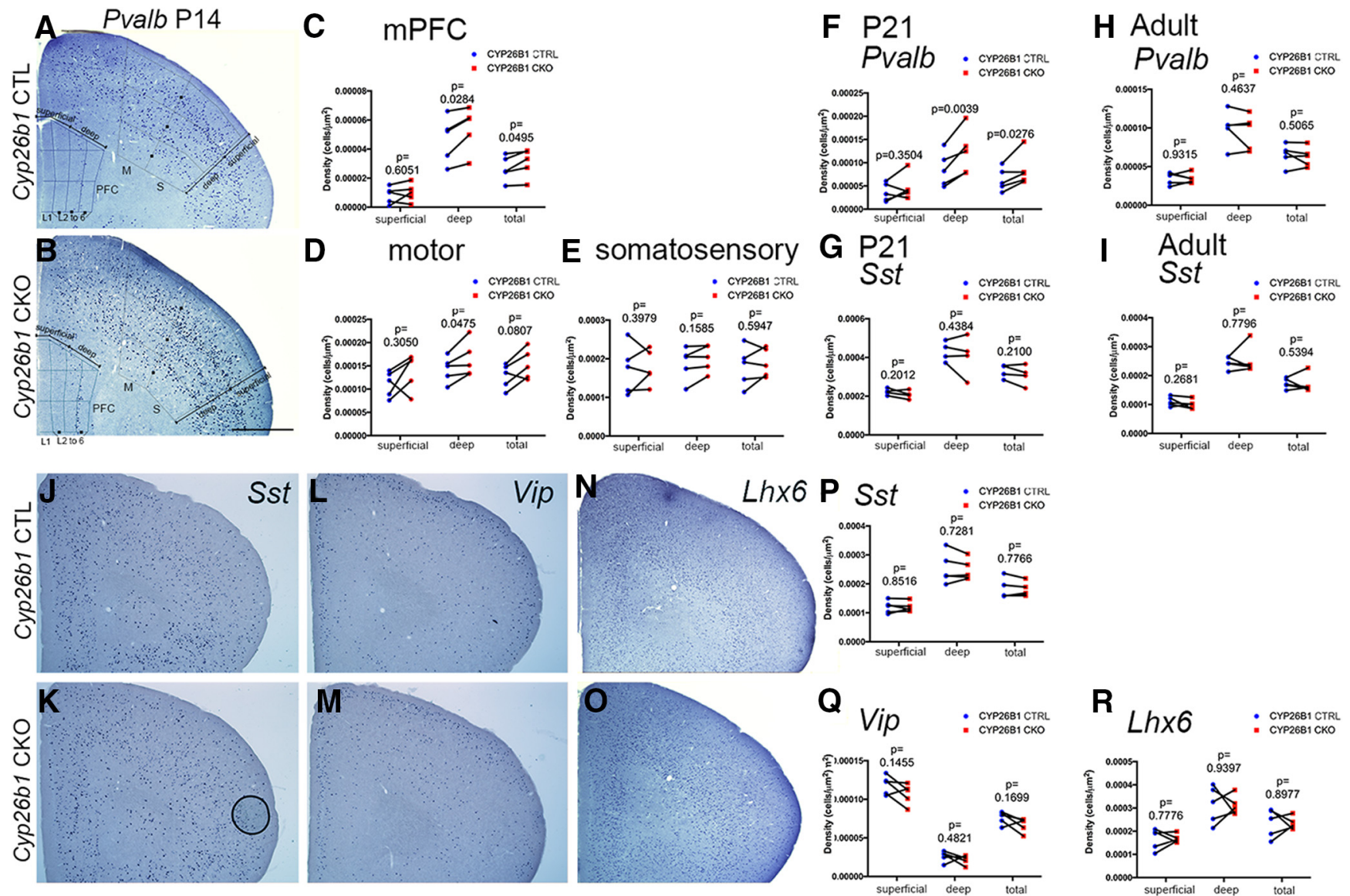

Figure 5. Increased Pvalb-expressing interneurons in medial PFC of Cyp26b1 knock-out mice. $\boldsymbol{A}, \boldsymbol{B}$, In situ hybridization of frontal sections of P14 Cyp26b1 conditional knock-out mice $(\boldsymbol{B})$ and littermate controls $(\boldsymbol{A})$. Expression of $P$ valb mRNA is shown. See Materials and Methods on the binning of the medial PFC. Numbers of Pvalb-positive cells in the two superficial bins and two deep bins were added together and compared separately between Cyp26b1 mutants and littermate controls. $\boldsymbol{C}-\boldsymbol{E}$, Result of paired ratio $t$ tests for cell counts in the medial PFC $(\boldsymbol{C})$, motor cortex $(\boldsymbol{D})$, and somatosensory cortex $(\boldsymbol{E})$, all on the same frontal sections. Each line connecting red and blue dots represents a pair of brains analyzed in the same experiment $(n=5)$. The $p$ values of the ratio of paired $t$ tests for each layer (superficial, deep, total) are shown. In repeated-measures two-way ANOVA, the $p$ values for layer (superficial versus deep), pair (between control and knockout), and interactions (between layer and pair) are 0.0017, 0.0325, and 0.1416 (P14 in PFC); 0.0441, 0.0961 and 0.7807 (P14 in motor cortex); $0.1771,0.4751$, and 0.5496 (P14 in somatosensory cortex), respectively. Scale bar, $1 \mathrm{~mm}$. L1, layer 1 . $\boldsymbol{F}$, G, At P21, the density of Pvalb-expressing cells $(\boldsymbol{F})$, but not Sst-expressing cells $(\boldsymbol{G})$, is increased in Cyp26b1 conditional knock-out mice. In repeated-measures two-way ANOVA, the $p$ values for layer (superficial versus deep), pair (between control and knockout), and interactions (between layer and pair) are $0.0047,0.0287$, and 0.0637 (Pvalb); 0.0065, 0.3621 , and 0.7609 (Sst). $\boldsymbol{H}, \boldsymbol{I}$, No significant changes in the density of Pvalb- and Sst-expressing interneurons in medial PFC of adult (P56-P67) Cyp26b1 knock-out mice. Each line connecting red and blue dots represents a pair of brains analyzed in the same experiment $(n=4)$. The $p$ values of paired $t$ tests for individual layers are shown. $\boldsymbol{J}-\boldsymbol{R}$, No significant changes in the number of Sst-, Vip-, and Lhx6-expressing interneurons in medial PFC of Cyp26b1 knock-out mice at P14. J-O, In situ hybridization of frontal sections of P14 Cyp26b1 conditional knock-out mice $(\boldsymbol{J}, \boldsymbol{L}, \boldsymbol{N})$ and littermate controls $(\boldsymbol{K}, \boldsymbol{M}, \mathbf{O})$. Expression of Sst $(\boldsymbol{J}, \boldsymbol{K})$, Vip $(\boldsymbol{L}, \boldsymbol{M})$, and $\operatorname{Lhx} 6(\boldsymbol{N}, \mathbf{O})$ is shown. Binning and cell counts were performed as shown in $\boldsymbol{A}$ and $\boldsymbol{B}$. Scale bar, $1 \mathrm{~mm}$. $\boldsymbol{P}-\boldsymbol{R}, \mathrm{Result}$ of statistical analysis. Each line connecting red and blue dots represents a pair of brains analyzed in the same experiment $(n=5)$. The $p$ values of paired ratio $t$ test for individual layer are shown.

trols by using paired $t$ tests (Fig. 5D), but the difference was not significant with repeated-measures two-way ANOVA. More laterally, the putative somatosensory area also did not show a significant difference in density (Fig. $5 E)$, suggesting that in the CKO mice, the residual Cyp26b1 expression in layer 5 of lateral frontal cortex (Fig. $4 K)$ might have spared the normal density of Pvalbexpressing cells in lateral cortex. In the medial PFC, normal expression of Cyp26b1 is limited to layer 6, and CKO mice had no residual expression in more superficial layers. In contrast to Pvalb-expressing neurons, the density of Sst, Vip (derived from CGE), or Lhx6 (a general marker for MGE-derived interneurons)-expressing neurons was not significantly different in the CKO mice compared with controls (Fig. 5J-R). Furthermore, in adult brains, Pvalb-, Sst-, and Vip-expressing cells did not show a significant difference between the CKO and control mice (Fig. 5H,I). Together, these results indicate that transient expression of Cyp26b1 in layer 6 of medial PFC is specifically required for controlling the development of PV interneurons. This is consistent with a disproportionately high percentage of PV neurons responding to RA compared with SST 
neurons (Fig. 3). The lack of significant change in the density of Sst-, Vip-, or Lhx6-expressing cells suggests that CYP26B1 does not control the fate specification or the number of each interneuron type, but rather the rate of maturation of PV lineage cells specifically.

\section{Cyp26b1 is not expressed in early postnatal medial PFC in the absence of thalamus-PFC connectivity}

Because Cyp26b1 starts to be expressed in medial and ventral PFC when the reciprocal connections between the thalamus and the cortex are being established, we next asked whether the normal expression of Cyp26b1 depends on this connectivity. In our previous study, thalamus-specific deletion of the homeobox gene Gbx2 resulted in severe deficiency of thalamocortical and corticothalamic projections in sensory areas (Vue et al., 2013). Similar to sensory cortex, the PFC also showed a significant reduction in the staining of NetrinG1, a marker of thalamocortical axons (Nakashiba et al., 2002; Vue et al., 2013), in Gbx2 mutant mice at E16.5 (Fig. 6A,B). Placement of Dil crystals into the medial PFC of Gbx2 mutants and wild-type mice at P14 revealed that both retrograde labeling of thalamic neurons and anterograde labeling of corticothalamic axons were severely attenuated in Gbx2 mutants (Fig. 6C-F). These results demonstrate a robust reduction of reciprocal connectivity between the thalamus and PFC in Gbx2 mutant mice.

We then tested whether the expression of Cyp26b1 in the PFC is altered in Gbx2 mutant mice. Already at P2, the mutant cortex lacked the expression of Cyp26b1 in medial and ventral PFC (Fig. $6 K, P$ ), demonstrating that the onset of Cyp26b1 expression requires thalamocortical interactions. The deficiency of Cyp26b1 expression continued until P21, when the medial PFC expression of Cyp26b1 normally started to decline (Fig. 6N,S). In contrast, the expression of Cyp26b1 showed no alterations in layer 5 of the lateral frontal cortex, including the motor areas and agranular insula (Fig. $6 K-T$ ). The layer 6 marker Syt6 was still highly expressed in the frontal cortex of Gbx2 mutants (Fig. $6 U, X$ ), making it unlikely that cell loss in layer 6 was the cause of the reduced expression of Cyp26b1 in Gbx2 mutants. Lastly, Aldh1a3, which normally shows the onset of expression in medial PFC similar to that of Cyp26b1, was qualitatively unaffected in $G b x 2$ mutants (Fig. $6 \mathrm{~V}, \mathrm{Y}$ ). In summary, transient expression of Cyp26b1 in layer 6 of medial PFC was dependent on the connections between the thalamus and the cortex (Fig. $6 W, Z)$. Our results collectively suggest a novel, indirect role of the thalamus in regulating the neocortical interneuron development.

\section{Lack of thalamus-PFC connectivity results in early aberrancy of radial positioning of MGE-derived interneurons}

In sensory cortex, thalamocortical afferents affect the development of interneurons by a variety of mechanisms (Sugiyama et al., 2008; Marques-Smith et al., 2016; Tuncdemir et al., 2016; Zechel et al., 2016). However, roles of the thalamus in the development of PFC interneurons are unknown. Hence, we analyzed the distribution of MGEderived interneurons in medial PFC at P0 and P21. At P0,
LHX6-expressing, MGE-derived interneurons showed an altered radial distribution in medial PFC (Fig. 7A-D); there was an increase in the density of LHX6-positive cells in layer 6 and below, and a decrease in the middle layers (Fig. 7C), while the total density was not significantly different in mutant brains (Fig. 7D). These results on the neonatal PFC are remarkably similar to a recent report on sensory and motor cortex of thalamus-specific Gbx2 mutant mice (Zechel et al., 2016). Thus, there is an early, cortex-wide role of thalamocortical projections in controlling the radial distribution of MGE-derived interneurons. Because the altered neuronal positioning occurred before the onset of Cyp26b1 expression in medial PFC, these early roles are likely to be independent of the later role of the thalamus in regulating the development of $\mathrm{PV}$ interneurons via Cyp26b1. At P21, densities of Pvalb- and Sst- expressing interneurons in medial PFC, specifically in the middle layers and not in the most superficial and the deepest layers, were significantly reduced in Gbx2 mutant mice (Fig. 7E-G). This is consistent with the increased apoptosis of LHX6-expressing cells in Gbx2 mutants at P8 (Fig. $7 H$ ), which might reflect the reduced excitatory input onto MGE-derived interneurons in the absence of thalamocortical afferents (Wong et al., 2018).

\section{Induction of Cyp26b1 by the thalamus is independent of transmitter release from thalamocortical projection neurons}

How does the thalamus control the expression of Cyp26b1 in layer 6 neurons in medial PFC at early postnatal stages? One likely cue that mediates the role of the thalamus is the transmitter release from thalamocortical axons. To test whether the lack of transmitter release phenocopies the lack of the axon projections, we generated mutant mice in which TeNT is ectopically expressed specifically in thalamocortical projection neurons (Fig. 8). At E16.5, the expression of VAMP2, the cleavage target of TeNT, was dramatically reduced in thalamocortical axons expressing TeNT, while it was retained in corticofugal axons (Fig. $8 A-D, G-J)$. At $\mathrm{P} 8$, the expression of $R O R \beta$ in layer 4 of the primary somatosensory area was altered in TeNTexpressing mice, lacking the characteristic barrel-like pattern (Fig. $8 E, F$ ). This is consistent with a recent study on vGluT mutants (Li et al., 2013) and indicates the role of transmitter release in the formation of normal cytoarchitecture of the primary sensory cortex. In the PFC, however, the induction of Cyp26b1 in the medial and ventral PFC was not qualitatively affected in TeNT-expressing mice (Fig. 8K,L), implying a unique cellular mechanism that underlies the induction of Cyp26b1 expression in early postnatal PFC.

\section{Discussion}

In this study, we first demonstrated that Cyp26b1, which encodes an RA-degrading enzyme and a critical regulator of retinoid signaling (Duester, 2008; Rhinn and Dollé, 2012), is expressed in developing PFC in a temporally and regionally specific manner. We also showed that PV-expressing interneurons are the major cell population that normally responds to RA via the RAR/RXR receptors. Conditional deletion of Cyp26b1 in layer 6 of the frontal cortex resulted in an increased density of Pvalb- 


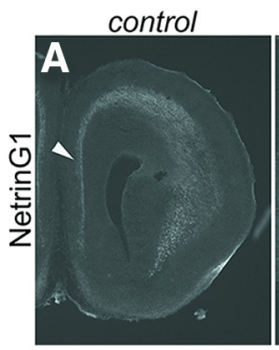

P2 Cyp26b1
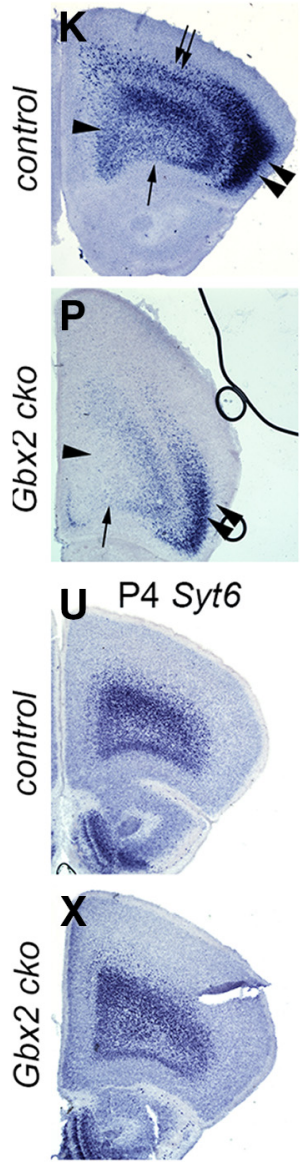

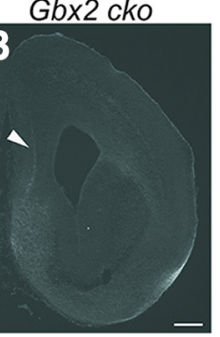

P4 Cyp26b1
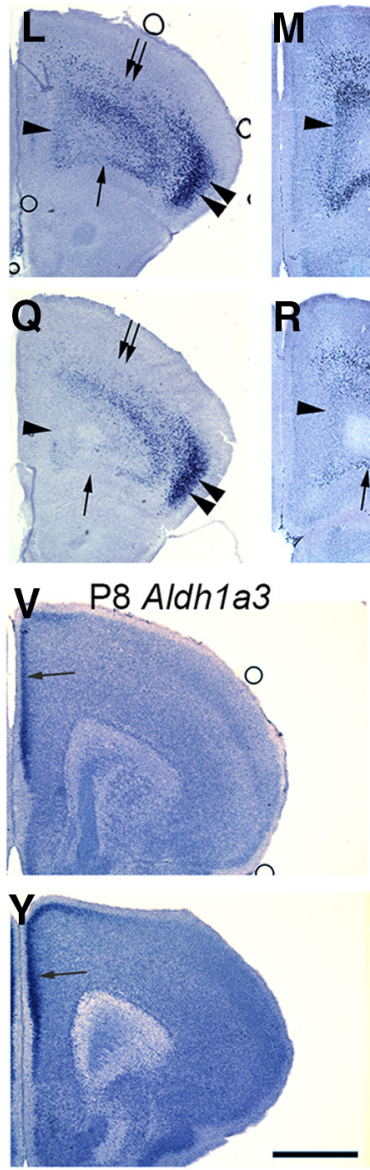

control

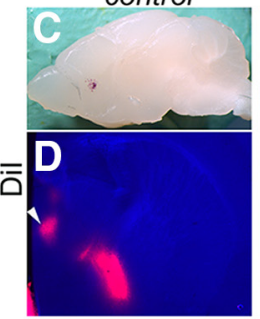

P14 Cyp26b1
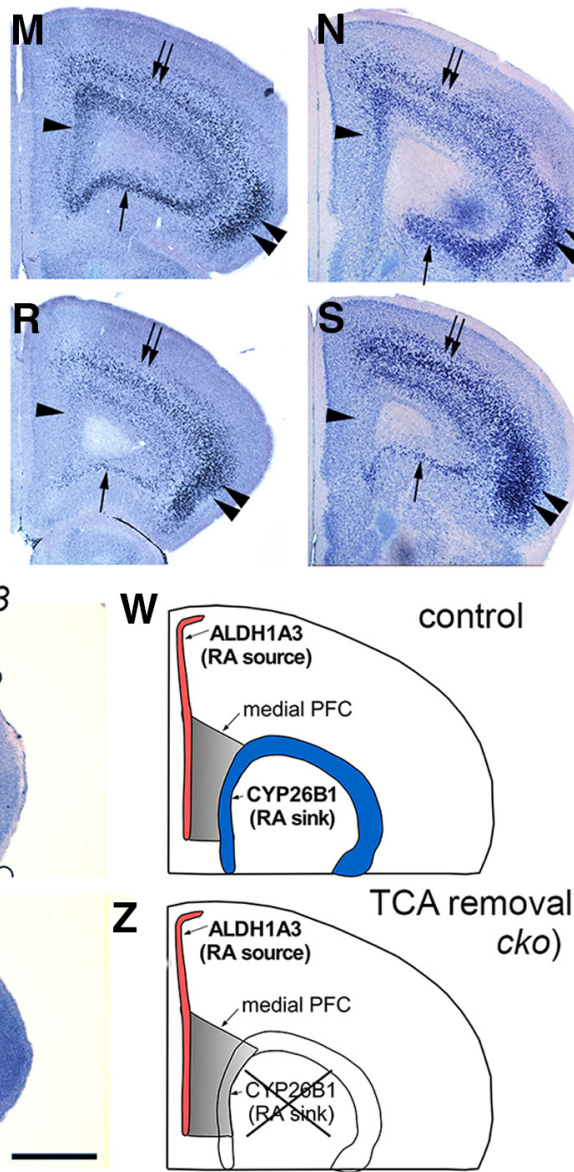

Gbx2 cko
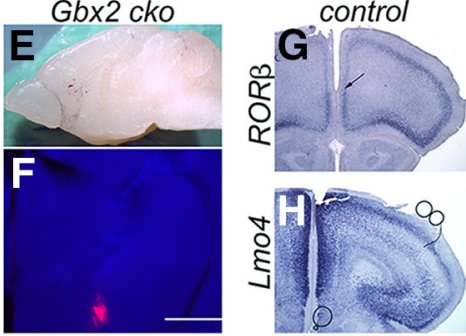

Gbx2 cko

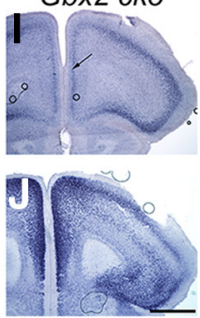

P35 Cyp26b1
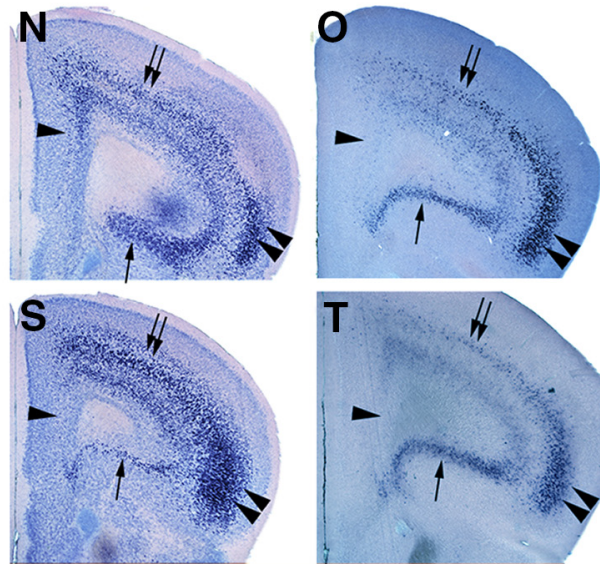

Figure 6. Transient expression of Cyp26b1 in the PFC does not occur in the absence of thalamus-cortex interactions in Gbx2 mutant mice. $\boldsymbol{A}-\boldsymbol{F}$, Thalamus-PFC disconnection in Gbx2 mutant mice. $\boldsymbol{A}, \boldsymbol{B}$, Immunostaining for NetrinG1 at E16.5. In control mice, NetrinG1-labeled thalamocortical axons are visible in coronal sections of frontal cortex. Arrowhead in $\boldsymbol{A}$ shows the medial PFC, where robust labeling is detected. In contrast, NetrinG1 labeling is barely detectable in the frontal cortex of Gbx2 mutant mice, including the medial PFC (B, arrowhead). Scale bar, $200 \mu \mathrm{m}$. $\boldsymbol{C}-\boldsymbol{F}$, Dil labeling at P14. $\boldsymbol{C}, \boldsymbol{D}$, Dil placement in medial PFC retrogradely labels medial thalamic nuclei in the control brains. $\boldsymbol{E}, \boldsymbol{F}$, In $G b x 2$ mutants, the label is severely reduced, indicating the deficiency of both thalamocortical and corticothalamic projections. G-J, Expression of $R O R \beta$ and $L m o 4$ is qualitatively normal in the PFC of Gbx2 mutant mice at P8. G, I, The expression of $R O R \beta$ in layer 4 is comparable between control (G) and Gbx2 mutant (cko) mice (I, arrows). $\boldsymbol{H}, \boldsymbol{J}$, Laminar expression patterns of $L m o 4$ also appear unchanged in $G b x 2$ mutants. Scale bar, $1 \mathrm{~mm}$. $\boldsymbol{K}-\boldsymbol{Z}$, Transient expression of Cyp26b1 in the PFC does not occur in the absence of thalamus-cortex interactions in $G b x 2$ mutant mice. $\boldsymbol{K}-\boldsymbol{T}$, in situ hybridization of frontal sections through PFC at various postnatal stages with a Cyp26b1 probe. $\boldsymbol{K}-\mathbf{O}$, In control mice $(\boldsymbol{K}-\mathbf{O})$, Cyp26b1 expression starts at P2 in medial (K, arrowhead) and ventral ( $\boldsymbol{K}$, single arrow) PFC, and continues until P14 ( $\boldsymbol{M})$. $\boldsymbol{N}, \boldsymbol{O}$, At P21, expression in medial PFC is reduced $(\boldsymbol{N})$ and is no longer detectable at P35 (O). $\mathbf{K}-\mathbf{O}$, In addition to medial and ventral PFC, Cyp26b1 is also expressed in lateral frontal cortex, including the motor and somatosensory areas (double arrows) and agranular insula (double arrowheads). $\boldsymbol{P}-\boldsymbol{T}$, In Gbx2 mutant mice, the expression of Cyp26b1 is not induced in medial or ventral PFC at P2 as well as at later stages, although ventral PFC does not appear to be affected at P14 and later. $\boldsymbol{P}-\boldsymbol{T}$, Expression in more superficial layer of lateral cortex (double arrows and double arrowheads) is not affected in Gbx2 mutant mice. $\boldsymbol{U}, \boldsymbol{X}$, Expression of the layer 6 marker Syt6 is not affected in Gbx2 mutant mice. $\boldsymbol{V}, \boldsymbol{Y}$, Expression of Aldh1a3 in layer 2 of medial PFC and anterior cingulate cortex (arrow) is not affected in Gbx2 mutant mice. Scale bar, $1 \mathrm{~mm}$. $\boldsymbol{W}, \boldsymbol{Z}$, Summary schematic for this figure. 

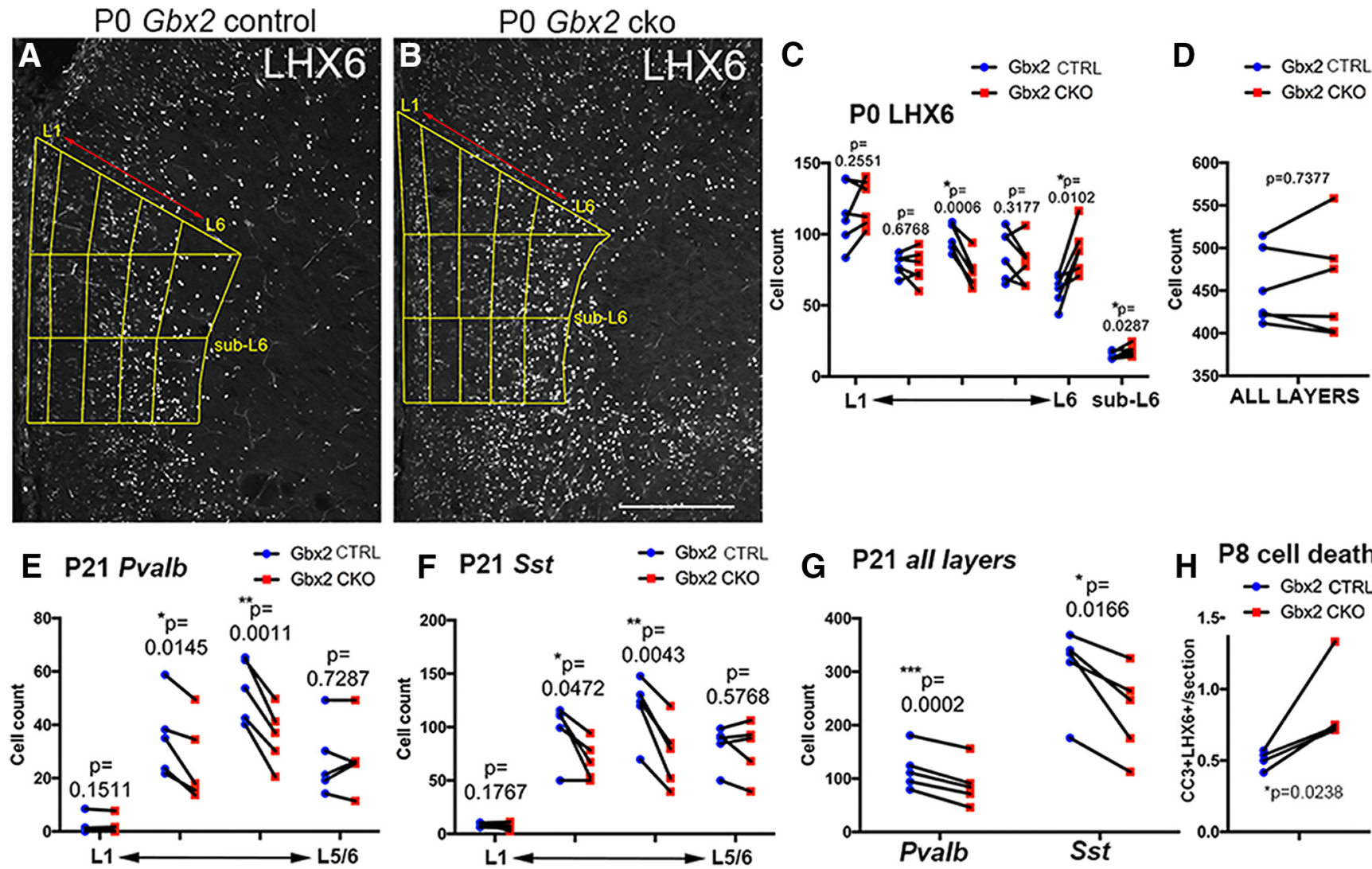

Figure 7. Abnormal radial distribution of MGE-derived interneurons in the medial PFC of neonatal and P21 Gbx2 mutant mice. $\boldsymbol{A}$, $\boldsymbol{B}$, Representative images of immunostaining for LHX6 in medial PFC of wild-type $(\boldsymbol{A})$ and Gbx2 mutant $(\boldsymbol{B})$ mice at P0. Binning is shown in yellow. Layer 1 (L1) was defined as the cell-sparse layer detected by DAPI staining. Layer 6 (L6) was defined as the layer with TBR1 staining on the same sections (data not shown). The intervening region was equally divided into three layers. Sublayer 6 was defined as the layer below layer 6. Scale bar, $200 \mu \mathrm{m}$. C, $\boldsymbol{D}$, Comparison of LHX6-positive cells in Gbx2 mutants (red dots) and wild-type littermates (blue dots) in medial PFC at P0. Each line connecting red and blue dots represents a pair of brains analyzed in the same experiment $(n=5)$. $\boldsymbol{C}$ shows laminar distribution pattern. The $p$ values of paired $t$ test for individual layer are shown. In repeated-measures two-way ANOVA, the $p$ values for layer, pair (between control and knockout), and interactions (between layer and pair) are 0.0001, 0.5950, and 0.0021, respectively. $\boldsymbol{D}$ shows the total number of Pvalb- and Sst-expressing neurons in all layers. The $p$ values of paired $t$ tests are shown. "Sub-L6" was defined as the region below the expression domain of TBR1, which was stained in all immunostaining slides for a reference. $* p<0.05, * * p<0.005$, ***p $<0.0005$. E-G, Comparison of Pvalb-positive and Sst-positive cells in Gbx2 mutants (red dots) and wild-type littermates (blue dots) in medial PFC at P21. Each line connecting red and blue dots represents a pair of brains analyzed in the same experiment $(n=5)$. $\boldsymbol{E}, \boldsymbol{F}$, Comparison of laminar distribution of Pvalb-expressing and Sst-expressing neurons, respectively, in Gbx2 mutant mice and littermate controls. Layer 1 was defined as the cell-sparse layer detected by DAPI staining. The remaining cortical wall was equally divided into three layers. The deepest layer (shown as "L5/6") contains the entire layer 6 and the deep part of layer 5 . G, The total number of $P$ valb-and Sst-expressing neurons in all layers. The $p$ values of a paired $t$ test for an individual layer are shown. In repeated-measures two-way ANOVA, the $p$ values for layer, pair (between control and knockout), and interactions (between layer and pair) are $<0.0001,0.0002$, and $0.0001(P v a l b) ;<0.0001,0.0247$, and 0.0001 (Sst), respectively. $\boldsymbol{H}$, Comparison of the numbers of cleaved caspase 3-positive, LHX6-positive cells in Gbx2 mutants (red dots), and wild-type littermates (blue dots) in medial PFC at P8. Each line connecting red and blue dots represents a pair of brains analyzed in the same experiment $(n=4)$. Each value is the mean of $7-15$ sections. The $p$ values of ratio paired $t$ tests are shown.

expressing neurons in deep layers of medial PFC during postnatal development. Expression of Cyp26b1 in the PFC depended on the connections between the cortex and the thalamus, but not on the transmitter release from thalamocortical axons. These results demonstrate a unique regulatory role of the thalamus in postnatal development of PV interneurons in the PFC (Fig. 9D-G).

\section{Roles of RA signaling in postnatal development of the medial PFC}

In early embryonic brain, RA controls rostrocaudal patterning of the hindbrain and spinal cord (Maden et al.,
1996; Dupé and Lumsden, 2001). Cells in the subventricular zone of the embryonic LGE express the RAsynthesizing enzyme ALDH1A3, and Aldh1a3-deficient mice had reduced expression of dopamine receptor D2 (Drd2) in nucleus accumbens (Molotkova et al., 2007) and reduced expression of Gad1 in embryonic GABAergic neurons in the striatum and the cortex (Chatzi et al., 2011), demonstrating a crucial role of RA in the early differentiation of embryonic GABAergic neurons. In contrast, much less is known about the roles of RA signaling in postnatal brain development. Systemic administration of RA into early postnatal mice caused an increased number of 

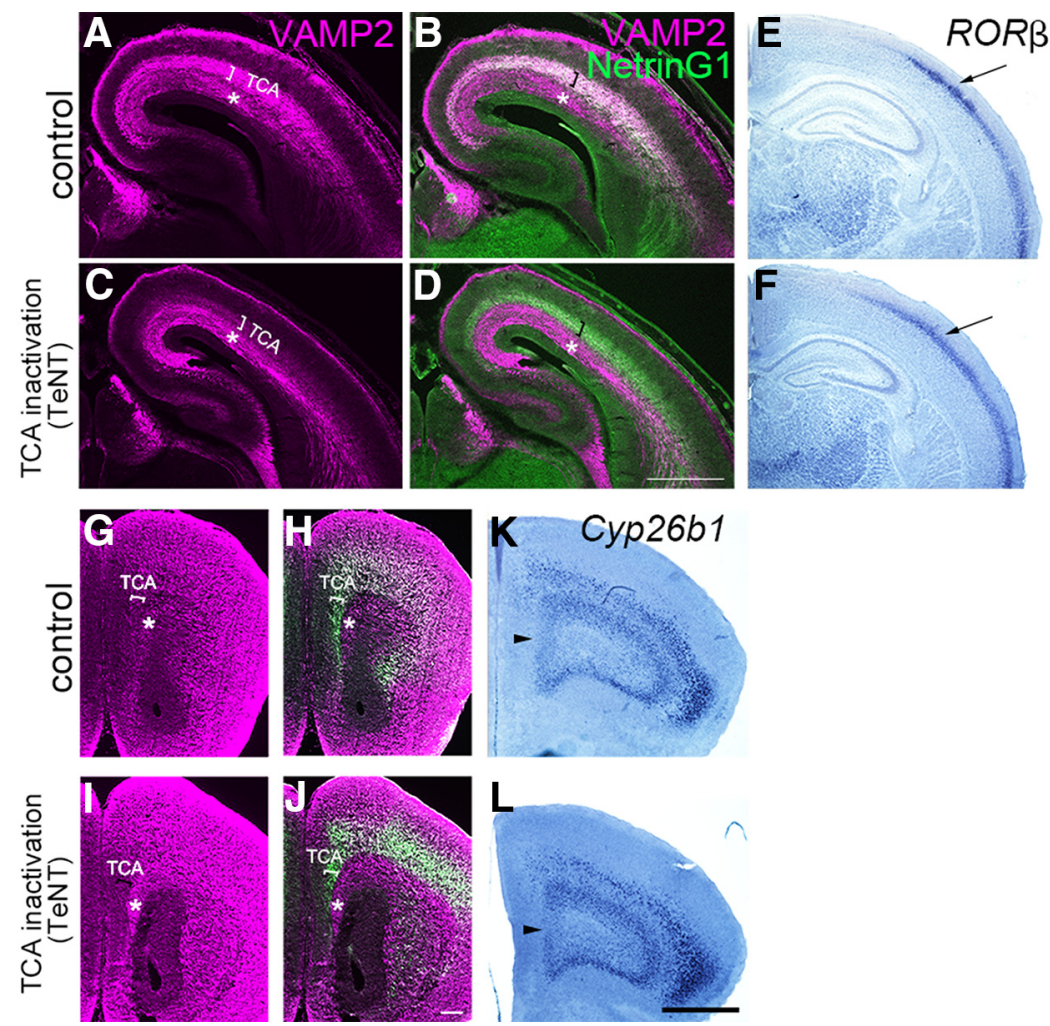

Figure 8. Normal induction of Cyp26b1 in PFC in mice expressing tetanus toxin light chain in thalamocortical axons. $\boldsymbol{A}-\boldsymbol{D}$, Immunostaining for VAMP2 on frontal sections of somatosensory cortex at E16.5 control $(\boldsymbol{A}, \boldsymbol{B})$ and mutant mice with ectopic expression of TeNT in thalamic neurons $(\boldsymbol{C}, \boldsymbol{D})$. TeNT expression leads to the deletion of VAMP2, specifically in thalamocortical axons at E16.5. Thalamocortical axons are shown by NetrinG1 staining (B, $\boldsymbol{D}$, green). In control brains, both thalamocortical (bracket, $\boldsymbol{A}-\boldsymbol{D})$ and corticofugal (asterisk, $\boldsymbol{A}-\boldsymbol{D}$ ) axons express VAMP2, whereas in TeNT-expressing mice, VAMP2 staining is specifically diminished in thalamocortical axons $(\boldsymbol{C}, \boldsymbol{D}$, bracket). Scale bar, $500 \mu \mathrm{m}$. $\boldsymbol{E}, \boldsymbol{F}$, Deletion of VAMP2 in thalamocortical axons results in the lack of the characteristic pattern of $R O R \beta$ expression in the barrel field of primary somatosensory cortex at P8 (arrow), similar to the defect found in Gbx2 mutant mice (Vue et al., 2013). G-J, Immunostaining for VAMP2 on frontal sections of prefrontal cortex at P0 control $(\boldsymbol{G}, \boldsymbol{H})$ and mutant mice with ectopic expression of TeNT in thalamic neurons $(\boldsymbol{I}, \boldsymbol{J})$. Similar to the somatosensory cortex, VAMP2 staining in thalamocortical axons is diminished in TeNT-expressing mice (I, $\boldsymbol{J}$, bracket). Scale bar, $200 \mu \mathrm{m}$. $\boldsymbol{K}$, $\boldsymbol{L}$, Expression of Cyp26b1 in medial (arrowhead) and ventral PFC is intact in TeNT-expressing mice (L), similar to control $(\boldsymbol{K})$, at P8. Scale bars: $\boldsymbol{G}, \boldsymbol{H}$, $\boldsymbol{I}, \boldsymbol{J}, 200 \mu \mathrm{m} ; \boldsymbol{E}, \boldsymbol{F}, \boldsymbol{K}, \boldsymbol{L}, 1 \mathrm{~mm}$.

calbindin-expressing neurons in the adult cingulate cortex (Luo et al., 2004), implicating a role of RA in early postnatal brain development. However, the role of RA in PFC development and the underlying cellular and molecular mechanisms had remained unknown.

Our current study revealed that in postnatal PFC, a significant subpopulation of PV interneurons are responsive to RA via RAR/RXR receptors, and that the lack of the RA-degrading enzyme CYP26B1 causes an increase in the density of Pvalb-expressing cells in medial PFC at P14 and P21. This phenotype should be independent of the proposed earlier roles of RA in tangential migration of GABA neurons (Crandall et al., 2011) because (1) most MGE-derived interneurons have completed the tangential migration to the cortex by birth; (2) Cyp26b1 is expressed only postnatally in the medial PFC and is not expressed in embryonic MGE or LGE (Fig. 1M,N); (3) Syt6-Cre mice do not cause recombination in MGE-derived interneurons (Fig. 4A,B); and (4) in Syt6 $6^{\mathrm{Cre} /+}$; Cyp26b $1^{\text {flox/flox }}$ mice, the expression of Cyp26b1 is not affected in regions outside of the frontal cortex, including the ventral telencephalon
(Fig. 4L-Q). In addition, the increased density of Pvalbpositive neurons in deep layers of medial PFC was not accompanied by their decrease in upper layers. This suggests that the radial dispersion of PV neurons, which follows their tangential migration, was also unaffected in Cyp26b1 mutants.

In adult brains, Cyp26b1 mutants no longer showed a significant increase in the density of $P v a l b$-positive neurons in medial PFC (Fig. 5H). In addition, the total density of MGE-derived interneurons marked by Lhx6 did not show a significant change throughout postnatal development. Thus, the most likely role of Cyp26b1 in the postnatal development of PV neurons in the medial PFC is to slow their rate of maturation by suppressing RA signaling. It is known that neurotrophin (e.g., BDNF) signaling and neuronal activity, likely mediated by NMDA receptors, play a role in the postnatal development of PV neurons (Huang et al., 1999; Itami et al., 2000; Patz et al., 2004; Woo and Lu, 2006; Belforte et al., 2010). Further studies are needed to investigate the relationship between these pathways and RA signaling. It will also be informative to 

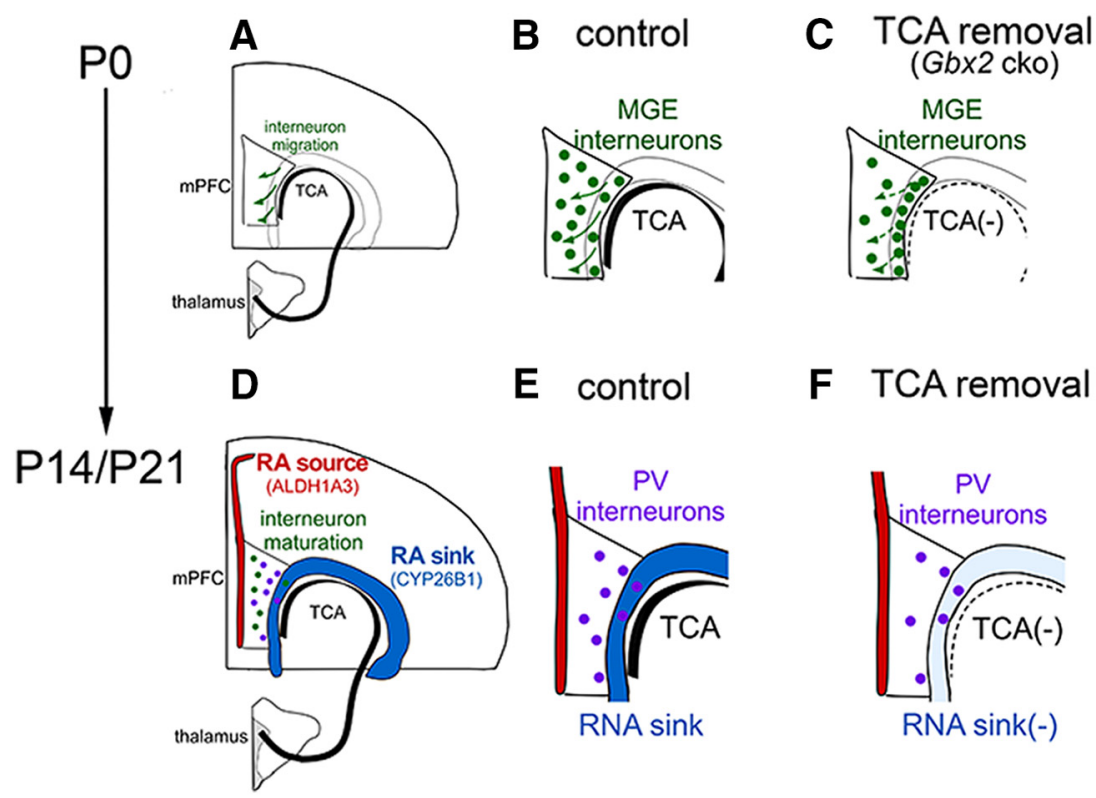

F TCA removal

\section{G RA sink removal (Cyp26b1 cko)}

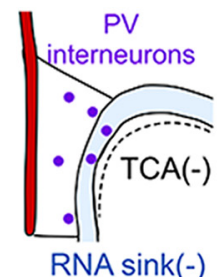

Figure 9. Schematic diagrams of the current finding. $\boldsymbol{A}-\boldsymbol{C}$, Embryonic roles of thalamocortical axons as observed in neonatal mice. $\boldsymbol{A}$, Thalamocortical axons reach the medial PFC (mPFC) by E16.5 and control migration of MGE-derived interneurons. $\boldsymbol{B}$, In normal neonatal mice, MGE-derived interneurons have largely completed tangential migration to the mPFC and have taken proper laminar positioning by radial dispersion (arrows). $\boldsymbol{C}$, In thalamus-specific Gbx2 mutant mice, radial positioning of MGE-derived interneurons are aberrant, resulting in their accumulation in layer 6 and below. D-G, Postnatal roles of thalamus-PFC interactions and RAdegrading enzyme CYP26B1 in the development of PV interneurons in the mPFC. $\boldsymbol{D}$, Early postnatal mPFC is positioned between the source of RA synthesis (layer 2, by ALDH1A3) and the RA-degrading "sink" (layer 6, by CYP26B1). The expression of both enzymes is induced early postnatally, but only Cyp26b1 is dependent on the connections with the thalamus. The main cell population that responds to RA in postnatal mPFC is PV interneurons, and their development is controlled by CYP26B1. $\boldsymbol{E}$, In normal postnatal mice, PV neurons mature and start to express Pvalb mRNA and PV protein mainly in deep layers of mPFC between P7 and P14. $\boldsymbol{F}$, In thalamus-specific Gbx2 mutant mice, Cyp26b1 is not induced in mPFC. The number of both Pvalb and Sst-expressing neurons is reduced in the middle layers at least partly due to the earlier defects in radial dispersion (described in $\mathbf{C}$ ). $\mathbf{G}$, In frontal cortex-specific Cyp26b1 mutant mice, lack of the RA sink in mPFC leads to an increased number of neurons that express Pvalb mRNA or PV protein in deep layers.

analyze various aspects of maturation of PV neurons including intrinsic electrophysiological properties, formation of perineuronal nets, and changes in gene expression (Okaty et al., 2009; Ueno et al., 2017).

\section{Universal and area-specific roles of the thalamus in neocortical development}

Previous studies have indicated that thalamocortical afferents instruct the establishment of area- and layerspecific gene expression as well as morphologic differentiation of excitatory neurons in primary visual and somatosensory cortex (Chou et al., 2013; Li et al., 2013; Vue et al., 2013; Moreno-Juan et al., 2017), and that some of the effects are dependent on the release of neurotransmitters from thalamocortical axons (Li et al., 2013). In addition to excitatory neurons, both SST and PV interneurons also depend on thalamic afferents for their maturation, likely via glutamatergic synaptic transmission (Sugiyama et al., 2008; Marques-Smith et al., 2016; Tuncdemir et al., 2016). In somatosensory, visual, and motor areas, thalamic afferents also control the radial positioning of MGE-derived interneurons before birth (Zechel et al., 2016). Are these roles universal throughout the cortex or is there area-specific regulation of cortical development by the thalamus? Due to the diverse patterns of gene expression (Jones, 2007; Nagalski et al., 2016;
Phillips et al., 2018) and axon projections (Clascá et al., 2012) among different thalamic nuclei and the early regional specification of the cortex before the arrival of thalamic axons (Rash and Grove, 2006; O'Leary et al., 2007; Hoch et al., 2009), it is expected that the nature of interactions with the thalamus varies among different cortical areas.

In fact, the expression of $\mathrm{ROR} \beta$ and $L m o 4$, which showed abnormal patterns in primary sensory cortex in the absence of thalamic input (Vue et al., 2013), was not impaired in the medial PFC (Fig. 6G-J). Instead, our current study has revealed a frontal cortex-specific regulation of Cyp26b1 by the thalamus at early postnatal stages. Interestingly, our TeNT model, in which the transmitter release from thalamocortical axons was blocked, was insufficient for recreating the loss of Cyp26b1 seen in the anatomic deficiency of thalamocortical connectivity. Therefore, the role of the thalamus in inducing Cyp26b1 expression in medial PFC neurons is likely independent of transmitter release that involves VAMP2 functions.

The current study also revealed an early role of the thalamus in regulating the radial positioning of MGEderived interneurons in neonatal PFC. The altered positioning of interneurons was similar to the phenotype seen in sensory and motor areas lacking the thalamic input (Zechel et al., 2016). This indicates that the early role of 
the thalamus in controlling the radial positions of cortical interneurons is shared between many neocortical areas (Fig. 9A-C). Importantly, abnormal radial distribution of cortical interneurons was also found in $L h \times 6$ mutant mice (Liodis et al., 2007), which suggests that the tangentialto-radial switch of interneuron migration in the cortex requires coordination of intrinsic and extrinsic signaling mechanisms during embryonic development.

It is intriguing that in postnatal Gbx2 mutant mice, even in the absence of normal induction of Cyp26b1 in medial PFC, the density of Pvalb-expressing neurons was decreased, not increased, unlike in Cyp26b1 mutants. This suggests that the thalamus plays additional roles, including the cell survival, in postnatal development of PV neurons other than by inducing Cyp26b1. This possibility is supported by our finding that there is an increased number of cleaved caspase 3-positive, LHX6-expressing cells in Gbx2 mutants at P8. It will be important to determine whether other known roles of the thalamus in postnatal regulation of the development of PV neurons in sensory cortex (Sugiyama et al., 2008; Marques-Smith et al., 2016; Tuncdemir et al., 2016) also apply to the PFC.

\section{Functional implications of altered PV neuron development in Cyp26b1 mutant mice}

At the systems level, RA regulates cortical synchrony during sleep (Maret et al., 2005), memory, and cognitive behaviors (Chiang et al., 1998; Aoto et al., 2008; Nomoto et al., 2012). In addition, aberrant RA signaling is associated with multiple psychiatric disorders including schizophrenia, bipolar disorder, and depression in humans (Goodman, 1998; Bremner et al., 2012; Haybaeck et al., 2015; Qi et al., 2015). Thus, understanding how RA functions in early postnatal brain development is important for determining the long-term consequences of the perturbations of this signaling pathway. Our results suggest that $\mathrm{RA}$ promotes postnatal development of PV neurons in medial PFC. PV neurons orchestrate activity in local circuits, which leads to synchronous network activity in the gamma band (Cardin et al., 2009; Sohal et al., 2009). Synchronous gamma-band activity in medial PFC is associated with the successful operation of working memory. In a mouse genetic model of schizophrenia that replicates the human 22q11.2 microdeletion syndrome (Karayiorgou et al., 1995), gamma synchrony and working memory performance were impaired (Sigurdsson et al., 2010), so was the development of PV interneurons (Meechan et al., 2012, 2015; Fénelon et al., 2013; Toritsuka et al., 2013). These findings link PV interneuron abnormalities to changes in prefrontal synchrony and working memory impairment in mouse models of neuropsychiatric disorders. Mutation of CYP26B1 in humans is a risk factor for schizophrenia that reaches genome-wide significance (Mistry et al., 2013; Schizophrenia Working Group of the Psychiatric Genomics Consortium, 2014). Therefore, it will be interesting to test whether the aberrant timecourse of PV neuron development in medial PFC causes altered synchrony and impairment of cognitive behaviors in Cyp26b1 mutant mice.

\section{References}

Aoto J, Nam Cl, Poon MM, Ting P, Chen L (2008) Synaptic signaling by all-trans retinoic acid in homeostatic synaptic plasticity. Neuron 60:308-320. CrossRef Medline

Arlotta P, Molyneaux BJ, Chen J, Inoue J, Kominami R, Macklis JD (2005) Neuronal subtype-specific genes that control corticospinal motor neuron development in vivo. Neuron 45:207-221. CrossRef Medline

Bartolini G, Ciceri G, Marín O (2013) Integration of GABAergic interneurons into cortical cell assemblies: lessons from embryos and adults. Neuron 79:849-864. CrossRef Medline

Batista-Brito R, Rossignol E, Hjerling-Leffler J, Denaxa M, Wegner M, Lefebvre V, Pachnis V, Fishell G (2009) The cell-intrinsic requirement of Sox6 for cortical interneuron development. Neuron 63: 466-481. CrossRef Medline

Belforte JE, Zsiros V, Sklar ER, Jiang Z, Yu G, Li Y, Quinlan EM, Nakazawa K (2010) Postnatal NMDA receptor ablation in corticolimbic interneurons confers schizophrenia-like phenotypes. Nat Neurosci 13:76-83. CrossRef Medline

Bluske KK, Vue TY, Kawakami Y, Taketo MM, Yoshikawa K, Johnson JE, Nakagawa $Y$ (2012) $\beta$-Catenin signaling specifies progenitor cell identity in parallel with Shh signaling in the developing mammalian thalamus. Development 139:2692-2702. CrossRef Medline

Bremner JD, Shearer KD, McCaffery PJ (2012) Retinoic acid and affective disorders: the evidence for an association. J Clin Psychiatry 73:37-50. CrossRef Medline

Caballero A, Tseng KY (2016) GABAergic Function as a Limiting Factor for Prefrontal Maturation during Adolescence. Trends Neurosci 39:441-448. CrossRef Medline

Cardin JA, Carlén M, Meletis K, Knoblich U, Zhang F, Deisseroth K, Tsai LH, Moore Cl (2009) Driving fast-spiking cells induces gamma rhythm and controls sensory responses. Nature 459:663-667. CrossRef Medline

Chatzi C, Brade T, Duester G (2011) Retinoic acid functions as a key GABAergic differentiation signal in the basal ganglia. PLoS Biol 9:e1000609. CrossRef Medline

Chen B, Schaevitz LR, McConnell SK (2005) Fezl regulates the differentiation and axon targeting of layer 5 subcortical projection neurons in cerebral cortex. Proc Natl Acad Sci U S A 102:1718417189. CrossRef Medline

Chen N, Napoli JL (2008) All-trans-retinoic acid stimulates translation and induces spine formation in hippocampal neurons through a membrane-associated RARalpha. FASEB J 22:236-245. CrossRef Medline

Chiang MY, Misner D, Kempermann G, Schikorski T, Giguère V, Sucov HM, Gage FH, Stevens CF, Evans RM (1998) An essential role for retinoid receptors RARbeta and RXRgamma in long-term potentiation and depression. Neuron 21:1353-1361. CrossRef Medline

Chou SJ, Babot Z, Leingärtner A, Studer M, Nakagawa Y, O'Leary DD (2013) Geniculocortical input drives genetic distinctions between primary and higher-order visual areas. Science 340:12391242. CrossRef Medline

Chu J, Anderson SA (2015) Development of cortical interneurons. Neuropsychopharmacology 40:16-23. CrossRef Medline

Clascá F, Rubio-Garrido P, Jabaudon D (2012) Unveiling the diversity of thalamocortical neuron subtypes. Eur J Neurosci 35:15241532. CrossRef Medline

Crandall JE, Goodman T, McCarthy DM, Duester G, Bhide PG, Dräger UC, McCaffery P (2011) Retinoic acid influences neuronal migration from the ganglionic eminence to the cerebral cortex. $J$ Neurochem 119:723-735. CrossRef Medline

Duester G (2008) Retinoic acid synthesis and signaling during early organogenesis. Cell 134:921-931. CrossRef Medline

Dupé V, Lumsden A (2001) Hindbrain patterning involves graded responses to retinoic acid signalling. Development 128:21992208. Medline

Fénelon K, Xu B, Lai CS, Mukai J, Markx S, Stark KL, Hsu PK, Gan WB, Fischbach GD, MacDermott AB, Karayiorgou M, Gogos JA 
(2013) The pattern of cortical dysfunction in a mouse model of a schizophrenia-related microdeletion. J Neurosci 33:14825-14839. CrossRef Medline

Fogarty M, Grist M, Gelman D, Marín O, Pachnis V, Kessaris N (2007) Spatial genetic patterning of the embryonic neuroepithelium generates GABAergic interneuron diversity in the adult cortex. J Neurosci 27:10935-10946. CrossRef Medline

Gonchar Y, Wang Q, Burkhalter A (2007) Multiple distinct subtypes of GABAergic neurons in mouse visual cortex identified by triple immunostaining. Front Neuroanat 1:3. CrossRef Medline

Gong S, Zheng C, Doughty ML, Losos K, Didkovsky N, Schambra UB, Nowak NJ, Joyner A, Leblanc G, Hatten ME, Heintz N (2003) A gene expression atlas of the central nervous system based on bacterial artificial chromosomes. Nature 425:917-925. CrossRef Medline

Gonzalez-Burgos G, Cho RY, Lewis DA (2015) Alterations in cortical network oscillations and parvalbumin neurons in schizophrenia. Biol Psychiatry 77:1031-1040. CrossRef Medline

Gonzalez-Quevedo R, Lee Y, Poss KD, Wilkinson DG (2010) Neuronal regulation of the spatial patterning of neurogenesis. Dev Cell 18:136-147. CrossRef Medline

Goodman AB (1998) Three independent lines of evidence suggest retinoids as causal to schizophrenia. Proc Natl Acad Sci U S A 95:7240-7244. Medline

Hashemi E, Ariza J, Rogers H, Noctor SC, Martínez-Cerdeño V (2018) The number of parvalbumin-expressing interneurons is decreased in the prefrontal cortex in autism. Cereb Cortex 28:690. CrossRef

Haybaeck J, Postruznik M, Miller CL, Dulay JR, Llenos IC, Weis S (2015) Increased expression of retinoic acid-induced gene 1 in the dorsolateral prefrontal cortex in schizophrenia, bipolar disorder, and major depression. Neuropsychiatr Dis Treat 11:279-289. CrossRef Medline

Hernandez RE, Putzke AP, Myers JP, Margaretha L, Moens CB (2007) Cyp26 enzymes generate the retinoic acid response pattern necessary for hindbrain development. Development 134:177-187. CrossRef Medline

Hevner RF, Shi L, Justice N, Hsueh Y, Sheng M, Smiga S, Bulfone A, Goffinet AM, Campagnoni AT, Rubenstein JL (2001) Tbr1 regulates differentiation of the preplate and layer 6. Neuron 29:353-366. CrossRef Medline

Hoch RV, Rubenstein JL, Pleasure S (2009) Genes and signaling events that establish regional patterning of the mammalian forebrain. Semin Cell Dev Biol 20:378-386. CrossRef Medline

Hsu YW, Wang SD, Wang S, Morton G, Zariwala HA, de la Iglesia HO, Turner EE (2014) Role of the dorsal medial habenula in the regulation of voluntary activity, motor function, hedonic state, and primary reinforcement. J Neurosci 34:11366-11384. CrossRef Medline

Hu JS, Vogt D, Sandberg M, Rubenstein JL (2017) Cortical interneuron development: a tale of time and space. Development 144: 3867-3878. CrossRef Medline

Huang ZJ, Kirkwood A, Pizzorusso T, Porciatti V, Morales B, Bear MF, Maffei L, Tonegawa S (1999) BDNF regulates the maturation of inhibition and the critical period of plasticity in mouse visual cortex. Cell 98:739-755. CrossRef Medline

Inamura N, Kimura T, Tada S, Kurahashi T, Yanagida M, Yanagawa Y, Ikenaka K, Murakami F (2012) Intrinsic and extrinsic mechanisms control the termination of cortical interneuron migration. $J$ Neurosci 32:6032-6042. CrossRef Medline

Itami C, Mizuno K, Kohno T, Nakamura S (2000) Brain-derived neurotrophic factor requirement for activity-dependent maturation of glutamatergic synapse in developing mouse somatosensory cortex. Brain Res 857:141-150. CrossRef Medline

Jones EG (2007) The thalamus. Cambridge: Cambridge UP.

Karayiorgou M, Morris MA, Morrow B, Shprintzen RJ, Goldberg R, Borrow J, Gos A, Nestadt G, Wolyniec PS, Lasseter VK (1995) Schizophrenia susceptibility associated with interstitial deletions of chromosome 22q11. Proc Natl Acad Sci U S A 92:7612-7616. CrossRef Medline
Li H, Fertuzinhos S, Mohns E, Hnasko TS, Verhage M, Edwards R, Sestan N, Crair MC (2013) Laminar and columnar development of barrel cortex relies on thalamocortical neurotransmission. Neuron 79:970-986. CrossRef Medline

Li JY, Lao Z, Joyner AL (2002) Changing requirements for Gbx2 in development of the cerebellum and maintenance of the mid/ hindbrain organizer. Neuron 36:31-43. CrossRef Medline

Liodis P, Denaxa M, Grigoriou M, Akufo-Addo C, Yanagawa $Y$, Pachnis V (2007) Lhx6 activity is required for the normal migration and specification of cortical interneuron subtypes. J Neurosci 27:3078-3089. CrossRef Medline

Luo T, Wagner E, Crandall JE, Dräger UC (2004) A retinoic-acid critical period in the early postnatal mouse brain. Biol Psychiatry 56:971-980. CrossRef Medline

Ma T, Zhang Q, Cai Y, You Y, Rubenstein JL, Yang Z (2012) A subpopulation of dorsal lateral/caudal ganglionic eminencederived neocortical interneurons expresses the transcription factor Sp8. Cereb Cortex 22:2120-2130. CrossRef Medline

Maden M, Gale E, Kostetskii I, Zile M (1996) Vitamin A-deficient quail embryos have half a hindbrain and other neural defects. Curr Biol 6:417-426. CrossRef Medline

Madisen L, Zwingman TA, Sunkin SM, On SW, Zariwala HA, Gu H, $\mathrm{Ng}$ LL, Palmiter RD, Hawrylycz MJ, Jones AR, Lein ES, Zeng H (2010) A robust and high-throughput Cre reporting and characterization system for the whole mouse brain. Nat Neurosci 13:133140. CrossRef Medline

Maret S, Franken P, Dauvilliers Y, Ghyselinck NB, Chambon P, Taft M (2005) Retinoic acid signaling affects cortical synchrony during sleep. Science 310:111-113. CrossRef Medline

Marques-Smith A, Lyngholm D, Kaufmann AK, Stacey JA, HoerderSuabedissen A, Becker EB, Wilson MC, Molnár Z, Butt SJ (2016) A transient translaminar GABAergic interneuron circuit connects thalamocortical recipient layers in neonatal somatosensory cortex. Neuron 89:536-549. CrossRef Medline

Meechan DW, Rutz HL, Fralish MS, Maynard TM, Rothblat LA, LaMantia AS (2015) Cognitive ability is associated with altered medial frontal cortical circuits in the LgDel mouse model of 22q11.2DS. Cereb Cortex 25:1143-1151. CrossRef Medline

Meechan DW, Tucker ES, Maynard TM, LaMantia AS (2012) Cxcr4 regulation of interneuron migration is disrupted in 22q11.2 deletion syndrome. Proc Natl Acad Sci U S A 109:18601-18606. CrossRef Medline

Mistry M, Gillis J, Pavlidis P (2013) Genome-wide expression profiling of schizophrenia using a large combined cohort. Mol Psychiatry 18:215-225. CrossRef Medline

Miyoshi G, Butt SJ, Takebayashi H, Fishell G (2007) Physiologically distinct temporal cohorts of cortical interneurons arise from telencephalic Olig2-expressing precursors. J Neurosci 27:7786-7798. CrossRef Medline

Miyoshi G, Fishell G (2011) GABAergic interneuron lineages selectively sort into specific cortical layers during early postnatal development. Cereb Cortex 21:845-852. CrossRef Medline

Molotkova N, Molotkov A, Duester G (2007) Role of retinoic acid during forebrain development begins late when Raldh3 generates retinoic acid in the ventral subventricular zone. Dev Biol 303:601610. CrossRef Medline

Moreno-Juan V, Filipchuk A, Antón-Bolaños N, Mezzera C, Gezelius $\mathrm{H}$, Andrés B, Rodríguez-Malmierca L, Susín R, Schaad O, Iwasato T, Schüle R, Rutlin M, Nelson S, Ducret S, Valdeolmillos M, Rijli FM, López-Bendito G (2017) Prenatal thalamic waves regulate cortical area size prior to sensory processing. Nat Commun 8:14172. CrossRef Medline

Nagalski A, Puelles L, Dabrowski M, Wegierski T, Kuznicki J, Wisniewska MB (2016) Molecular anatomy of the thalamic complex and the underlying transcription factors. Brain Struct Funct 221: 2493-2510. CrossRef Medline

Nakashiba T, Nishimura S, Ikeda T, Itohara S (2002) Complementary expression and neurite outgrowth activity of netrin-G subfamily members. Mech Dev 111:47-60. CrossRef Medline 
Nakazawa K, Zsiros V, Jiang Z, Nakao K, Kolata S, Zhang S, Belforte JE (2012) GABAergic interneuron origin of schizophrenia pathophysiology. Neuropharmacology 62:1574-1583. CrossRef Medline

Ng L, Bernard A, Lau C, Overly CC, Dong HW, Kuan C, Pathak S, Sunkin SM, Dang C, Bohland JW, Bokil H, Mitra PP, Puelles L, Hohmann J, Anderson DJ, Lein ES, Jones AR, Hawrylycz M (2009) An anatomic gene expression atlas of the adult mouse brain. Nat Neurosci 12:356-362. CrossRef Medline

Nikouei K, Muñoz-Manchado AB, Hjerling-Leffler J (2016) BCL11B/ CTIP2 is highly expressed in GABAergic interneurons of the mouse somatosensory cortex. J Chem Neuroanat 71:1-5. CrossRef Medline

Nomoto M, Takeda Y, Uchida S, Mitsuda K, Enomoto H, Saito K, Choi T, Watabe AM, Kobayashi S, Masushige S, Manabe T, Kida $S$ (2012) Dysfunction of the RAR/RXR signaling pathway in the forebrain impairs hippocampal memory and synaptic plasticity. Mol Brain 5:8. CrossRef Medline

Nowicka D, Soulsby S, Skangiel-Kramska J, Glazewski S (2009) Parvalbumin-containing neurons, perineuronal nets and experience-dependent plasticity in murine barrel cortex. Eur $\mathrm{J}$ Neurosci 30:2053-2063. CrossRef Medline

O'Leary DD, Chou SJ, Sahara S (2007) Area patterning of the mammalian cortex. Neuron 56:252-269. CrossRef Medline

Okano J, Lichti U, Mamiya S, Aronova M, Zhang G, Yuspa SH, Hamada H, Sakai Y, Morasso MI (2012) Increased retinoic acid levels through ablation of Cyp26b1 determine the processes of embryonic skin barrier formation and peridermal development. J Cell Sci 125:1827-1836. CrossRef Medline

Okaty BW, Miller MN, Sugino K, Hempel CM, Nelson SB (2009) Transcriptional and electrophysiological maturation of neocortical fast-spiking GABAergic interneurons. J Neurosci 29:7040-7052. CrossRef Medline

Patz S, Grabert J, Gorba T, Wirth MJ, Wahle P (2004) Parvalbumin expression in visual cortical interneurons depends on neuronal activity and TrkB ligands during an early period of postnatal development. Cereb Cortex 14:342-351. CrossRef Medline

Paxinos G, Halliday GM, Watson C, Koutcherov Y, Wang H (2006) Atlas of the developing mouse brain at E17.5, P0 and P6. Amsterdam: Elsevier Academic.

Phillips JW, Schulmann A, Hara E, Liu C, Wang L, Shields B, Korff W, Lemire A, Dudman J, Nelson SB (2018) A single spectrum of neuronal identities across thalamus. bioRxiv. Advance online publication. Retrieved February 24, 2019. doi:10.1101/241315.

Powell SB, Sejnowski TJ, Behrens MM (2012) Behavioral and neurochemical consequences of cortical oxidative stress on parvalbumin-interneuron maturation in rodent models of schizophrenia. Neuropharmacology 62:1322-1331. CrossRef Medline

Qi XR, Zhao J, Liu J, Fang H, Swaab DF, Zhou JN (2015) Abnormal retinoid and TrkB signaling in the prefrontal cortex in mood disorders. Cereb Cortex 25:75-83. CrossRef Medline

Rash BG, Grove EA (2006) Area and layer patterning in the developing cerebral cortex. Curr Opin Neurobiol 16:25-34. CrossRef Medline

Rhinn M, Dollé P (2012) Retinoic acid signalling during development. Development 139:843-858. CrossRef Medline

Rossant J, Zirngibl R, Cado D, Shago M, Giguère V (1991) Expression of a retinoic acid response element-hsplacZ transgene defines specific domains of transcriptional activity during mouse embryogenesis. Genes Dev 5:1333-1344. CrossRef Medline

Schizophrenia Working Group of the Psychiatric Genomics Consortium (2014) Biological insights from 108 schizophrenia-associated genetic loci. Nature 511:421-427. CrossRef Medline

Schubert D, Martens GJ, Kolk SM (2015) Molecular underpinnings of prefrontal cortex development in rodents provide insights into the etiology of neurodevelopmental disorders. Mol Psychiatry 20:795809. CrossRef Medline
Sigurdsson T, Stark KL, Karayiorgou M, Gogos JA, Gordon JA (2010) Impaired hippocampal-prefrontal synchrony in a genetic mouse model of schizophrenia. Nature 464:763-767. CrossRef Medline

Sohal VS, Zhang F, Yizhar O, Deisseroth K (2009) Parvalbumin neurons and gamma rhythms enhance cortical circuit performance. Nature 459:698-702. CrossRef Medline

Sugiyama S, Di Nardo AA, Aizawa S, Matsuo I, Volovitch M, Prochiantz A, Hensch TK (2008) Experience-dependent transfer of Otx2 homeoprotein into the visual cortex activates postnatal plasticity. Cell 134:508-520. CrossRef Medline

Toritsuka M, Kimoto S, Muraki K, Landek-Salgado MA, Yoshida A, Yamamoto N, Horiuchi Y, Hiyama H, Tajinda K, Keni N, Illingworth E, Iwamoto T, Kishimoto T, Sawa A, Tanigaki K (2013) Deficits in microRNA-mediated Cxcr4/Cxcl12 signaling in neurodevelopmental deficits in a 22q11 deletion syndrome mouse model. Proc Natl Acad Sci U S A 110:17552-17557. CrossRef Medline

Tuncdemir SN, Wamsley B, Stam FJ, Osakada F, Goulding M, Callaway EM, Rudy B, Fishell G (2016) Early somatostatin interneuron connectivity mediates the maturation of deep layer cortical circuits. Neuron 89:521-535. CrossRef Medline

Ueno H, Suemitsu S, Okamoto M, Matsumoto Y, Ishihara T (2017) Parvalbumin neurons and perineuronal nets in the mouse prefrontal cortex. Neuroscience 343:115-127. CrossRef Medline

Van De Werd HJ, Rajkowska G, Evers P, Uylings HB (2010) Cytoarchitectonic and chemoarchitectonic characterization of the prefrontal cortical areas in the mouse. Brain Struct Funct 214:339353. CrossRef Medline

Vue TY, Aaker J, Taniguchi A, Kazemzadeh C, Skidmore JM, Martin DM, Martin JF, Treier M, Nakagawa Y (2007) Characterization of progenitor domains in the developing mouse thalamus. J Comp Neurol 505:73-91. CrossRef Medline

Vue TY, Bluske K, Alishahi A, Yang LL, Koyano-Nakagawa N, Novitch B, Nakagawa $Y$ (2009) Sonic hedgehog signaling controls thalamic progenitor identity and nuclei specification in mice. $J$ Neurosci 29:4484-4497. CrossRef Medline

Vue TY, Lee M, Tan YE, Werkhoven Z, Wang L, Nakagawa Y (2013) Thalamic control of neocortical area formation in mice. J Neurosci 33:8442-8453. CrossRef Medline

Wagner E, Luo T, Dräger UC (2002) Retinoic acid synthesis in the postnatal mouse brain marks distinct developmental stages and functional systems. Cereb Cortex 12:1244-1253. CrossRef Medline

Wagner E, Luo T, Sakai Y, Parada LF, Dräger UC (2006) Retinoic acid delineates the topography of neuronal plasticity in postnatal cerebral cortex. Eur J Neurosci 24:329-340. CrossRef Medline

Wamsley B, Fishell G (2017) Genetic and activity-dependent mechanisms underlying interneuron diversity. Nat Rev Neurosci 18:299309. CrossRef Medline

Wong FK, Bercsenyi K, Sreenivasan V, Portalés A, Fernández-Otero M, Marín O (2018) Pyramidal cell regulation of interneuron survival sculpts cortical networks. Nature 557:668-673. CrossRef Medline

Woo NH, Lu B (2006) Regulation of cortical interneurons by neurotrophins: from development to cognitive disorders. Neuroscientist 12:43-56. CrossRef Medline

Yashiro K, Zhao X, Uehara M, Yamashita K, Nishijima M, Nishino J, Saijoh Y, Sakai Y, Hamada H (2004) Regulation of retinoic acid distribution is required for proximodistal patterning and outgrowth of the developing mouse limb. Dev Cell 6:411-422. CrossRef Medline

Zechel S, Nakagawa Y, Ibáñez CF (2016) Thalamo-cortical axons regulate the radial dispersion of neocortical GABAergic interneurons. Elife 5:e20770. CrossRef Medline

Zhang Y, Narayan S, Geiman E, Lanuza GM, Velasquez T, Shanks B, Akay T, Dyck J, Pearson K, Gosgnach S, Fan CM, Goulding M (2008) V3 spinal neurons establish a robust and balanced locomotor rhythm during walking. Neuron 60:84-96. CrossRef Medline 